Review

\title{
Modulating the microstructure and surface chemistry of carbocatalysts for oxidative and direct dehydrogenation: A review
}

\author{
Zhongkui Zhao*, Guifang Ge, Weizuo Li, Xinwen Guo, Guiru Wang \\ State Key Laboratory of Fine Chemicals, Department of Catalysis Chemistry and Engineering, School of Chemical Engineering, Dalian University of \\ Technology, Dalian 116024, Liaoning, China
}

\section{A R T I C L E I N F 0}

Article history:

Received 13 January 2016

Accepted 22 February 2016

Published 5 May 2016

\section{Keywords:}

Carbocatalysis

Microstructure

Surface chemistry

Modulation

Dehydrogenation

Olefin

\begin{abstract}
A B S T R A C T
The catalytic performance of solid catalysts depends on the properties of the catalytically active sites and their accessibility to reactants, which are significantly affected by the microstructure (morphology, shape, size, texture, and surface structure) and surface chemistry (elemental components and chemical states). The development of facile and efficient methods for tailoring the microstructure and surface chemistry is a hot topic in catalysis. This contribution reviews the state of the art in modulating the microstructure and surface chemistry of carbocatalysts by both bottom-up and top-down strategies and their use in the oxidative dehydrogenation (ODH) and direct dehydrogenation (DDH) of hydrocarbons including light alkanes and ethylbenzene to their corresponding olefins, important building blocks and chemicals like oxygenates. A concept of microstructure and surface chemistry tuning of the carbocatalyst for optimized catalytic performance and also for the fundamental understanding of the structure-performance relationship is discussed. We also highlight the importance and challenges in modulating the microstructure and surface chemistry of carbocatalysts in ODH and DDH reactions of hydrocarbons for the highly-efficient, energy-saving, and clean production of their corresponding olefins.
\end{abstract}

(c) 2016, Dalian Institute of Chemical Physics, Chinese Academy of Sciences. Published by Elsevier B.V. All rights reserved.

\section{Introduction}

Owing to their extensive use as chemical building blocks, olefins, including light olefins and styrene, are among the most important compounds in the chemical industry. Both light olefins and styrene are important monomers for polymer and copolymer synthesis. Light olefins are also the feedstock in the production of a vast array of chemicals including oxygenates like ethylene glycol, acetic acid, acetaldehyde, acetone, propylene oxide, ethylene oxide, 2-butanone, 1,2-epoxybutane, 2-butyl alcohol, etc. as well as important chemical intermedi- ates like propyl aldehyde, vinyl chloride, acrylonitrile [1,2]. The production of light olefins and styrene has attracted continuously growing interest in the past century and would have this position for a long time to come. Therefore, the catalytic dehydrogenation of hydrocarbons including light alkanes and ethylbenzene to olefins has attracted considerable attention in both academia and industry.

The traditional DDH process for the production of olefins is normally performed a $\mathrm{K}$ promoted Fe-based catalyst $[3,4]$. However, the commercially available K-Fe catalyst has many disadvantages like quick deactivation due to potassium loss,

\footnotetext{
* Corresponding author. Tel/Fax: +86-411-84986354; E-mail: zkzhao@dlut.edu.cn

This work was supported by the National Natural Science Foundation of China (21276041), the Program for New Century Excellent Talents in University of Ministry of Education of China (NCET-12-0079), the Natural Science Foundation of Liaoning Province (2015020200) and the Fundamental Research Funds for the Central Universities (DUT15LK41). DOI: 10.1016/S1872-2067(15)61065-8 | http://www.sciencedirect.com/science/journal/18722067 | Chin. J. Catal., Vol. 37, No. 5, May 2016
} 
unstable $\mathrm{Fe}^{3+}$ state, coke deposition, and health injuries to human beings caused by the $\mathrm{Cr}$ used in this catalytic system. Moreover, the introduction of superheated steam into the feed is needed to give a thermodynamic driving force as heat due to its endothermic character (for DDH of ethylbenzene at $600{ }^{\circ} \mathrm{C}$, $\Delta H_{600}=126.6 \mathrm{~kJ} / \mathrm{mol}$ ), to shift the chemical equilibrium to higher styrene conversion. This also inhibits quick deactivation caused by coke deposition. However, the used excess steam (about 2-3:1 for current technology) leads to high energy consumption $[3,4]$. Oxidative dehydrogenation (ODH) is an alternative process with improved energy efficiency owing to its exothermic characteristic (for ODH of ethylbenzene at $600{ }^{\circ} \mathrm{C}$, $\Delta H_{600}=-111.1 \mathrm{~kJ} / \mathrm{mol}$ ) [4-6]. However, a low selectivity due to the deep oxidation of alkane and the formed olefins is a bottle-neck for its application in olefin production since the formed olefins are more active than the starting hydrocarbons. The search for new catalyst systems is highly desirable, but remains a challenge.

The development of low cost sustainable catalysts with high catalytic activity, selectivity, and stability under mild conditions remains at the heart of modern material chemistry, green chemistry, and catalysis from academic and practical aspects [7-9]. Although metal catalysts have currently played major roles in many industrial transformation processes, they suffer from many inherent disadvantages such as low availability, high cost, susceptibility to gas poisoning, detrimental effects on our environment, and residual metal in the products [10-13]. Owing to broad availability, environmental acceptability, corrosion resistance, and unique surface properties, nanocarbon materials are a promising and sustainable low cost metal-free alternative to metal-based catalysts for organic synthesis [14-20], hydrogen production [21,22], photo-degradation of organic pollutants $[23,24]$, the crucial oxygen reduction reaction in fuel cells [25-27], and as the counter electrode catalyst for solar cells [28,29]. Nowadays, carbocatalysis has already attracted great attention throughout the world, and has become the forefront and a hot topic in heterogeneous catalysis and sustainable chemistry [10,11,30-42].

In fact, carbon materials, especially nanocarbons, have been reported in both ODH and DDH of hydrocarbons including that of light alkanes and ethylbenzene to their corresponding olefins. Numerous studies have been focused on the ODH process over different carbocatalysts, which exhibited many merits in comparison to DDH, such as higher activity and lower energy consumption, and not limited by thermodynamics due to its exothermic process $[4,5]$. However, it is worthwhile to point out that in fact the ODH process has some significant disadvantages. The use of a mixture containing oxygen and hydrocarbons leads to a low thermal stability of the carbocatalysts due to serious damage by oxygen under the relatively harsh reaction conditions, and there is a safety issue due to the use of a mixture containing oxygen and hydrocarbons, besides the above mentioned low selectivity owing to side reactions such as the combustion of hydrocarbons [43-46]. Recently, the carbon material catalyzed DDH of ethylbenzene to styrene under oxygen- and steam-free conditions was first reported by employing nanodiamond as an efficient metal-free catalyst, which has a fascinating prospect for clean and energy-saving styrene production [47]. The exciting results have inspired researchers to develop novel and efficient carbon-based catalysts for the DDH reactions of different hydrocarbons including light alkanes and ethylbenzene. In the DDH process, the carbocatalysts exhibit outstanding coke tolerance behaviour in the absence of steam and oxidant in comparison to the industrially used K-Fe catalysts. In addition, DDH also eliminates the low thermal stability issues of ODH carbocatalysts, and the insufficient selectivity and the risks in handing flammable mixture including hydrocarbon and oxygen [47]. However, improvement in the catalytic activity of the carbocatalysts for DDH process is urgently required.

From the above, ODH and DDH as two ways for olefin production have demonstrated great potential for future industrial application. However, there still exist many issues to be resolved before the industrial use of carbocatalyst-mediated dehydrogenation processes of hydrocarbons, either ODH or DDH, can be realized. Especially, improvement in selectivity and stability for ODH and the enhancement in catalytic activity for DDH process are urgently required.

The catalytic performance of solid catalysts depends on the properties of the active sites and their accessibility to reactants, which are significantly affected by the microstructure (morphology, shape, size, texture, and surface structure) and surface chemical properties (elemental components and chemical states) [48-58]. This work reviews the state of the art in modulation of the microstructure and surface chemistry of carbocatalysts through both bottom-up and top-down approaches for both the ODH and DDH of hydrocarbons, including light alkanes and ethylbenzene to their corresponding olefins. We highlight the importance and challenges in modulating the microstructure and surface chemistry of carbocatalysts in both $\mathrm{ODH}$ and DDH reactions of hydrocarbons for applications in olefin production.

\section{Active sites and mechanism}

The surface chemical components, state, and structure of carbocatalysts are quite complex, which make it very difficult to identify and quantify the catalytically active sites for the dehydrogenation process. Since the catalytically active sites are very important for catalytic reactions, many studies have focused on their identification and quantification by employing powerful techniques like temperature programmed desorption (TPD), X-ray photoelectron spectroscopy (XPS), Fourier Transform infrared spectroscopy (FT-IR), microcalorimetric analysis (MCA), chemical titration analysis, model catalysts experiment, and density functional theory (DFT) calculations [4,5,59-80]. Some fruitful results have been achieved which provided helpful guidance for designing and manipulating the microstructure and surface chemistry of carbocatalysts for olefin production from hydrocarbons through either the ODH or DDH process.

\subsection{ODH reaction}

General consensus in previously reported results of 
nanostructured carboncatalysts for ODH of hydrocarbons to olefins is that the oxygen-containing functionalities generated during synthesis and the $\mathrm{ODH}$ reaction process are responsible for the catalytic activity of carbocatalysts in ODH reactions by abstracting hydrogen from the hydrocarbons to form their corresponding unsaturated hydrocarbons [61,73]. However, the total oxygen content does not have a strong relationship with ODH catalytic performance but to the unselective $\mathrm{CO}_{x}$ formation [62]. The ketonic carbonyl groups in ketones and quinones have been identified as catalytically active sites for the $\mathrm{ODH}$ process of hydrocarbons to their corresponding olefins, but the defects, edges, and the other oxygen-containing groups on the carbon materials are detrimental to the selective production of alkenes owing to their too high activity for overoxidation $[46,63,64-70]$. The introduction of phosphate can efficiently modulate the oxygen-containing functional groups, defects, and their distribution [63]. Recently, Figueiredo and coworkers [66] identified the positive catalytic role of ketonic carbonyl groups and the negative role of carboxylic anhydride groups in the ODH reaction. Zhang and coworkers [65] exhibited that when $\mathrm{CO}_{2}$ was used as a soft oxidant for the $\mathrm{ODH}$ reaction, the defects on the exposed edge and terminals of the nanocarbons favored the ODH reaction. It was reported that the produced hydroxyl groups induced by the defects on the exposed surface through an alkali-assisted hydroxylation can be easily oxidized to form carbonyl groups, which can activate the $\mathrm{C}-\mathrm{H}$ bond in hydrocarbons to produce olefins and the carbonyl groups are simultaneously converted into hydroxyl groups. The hydroxyl groups can be re-oxidized into carbonyl groups, and thus the catalytic cycle can be maintained [65]. It was found that graphitic nitrogen plays a determining role in enhancing their activity by speeding up the activation of oxygen and decreasing the overall activation energy of the ODH reaction $[59,66,71]$. This was ascribed to the improvement in the nucleophilicity of ketonic $\mathrm{C}=\mathrm{O}$ groups due to the increased electron density. The previously reported results have revealed that phosphate preferentially reacts with the phenol groups initially present on the nanodiamond surface, and then it selectively blocks the defect sites that lead to $\mathrm{CO}_{x}$ formation to give an increased propene selectivity. During this process, the catalyst active sites (ketonic carbonyl groups) were not affected [77]. Su and coworkers [78] identified that heteroatoms like B can suppress the formation of non-selective oxygen species, which increases the selectivity of nanocarbons for the ODH reaction. The in-depth understanding of catalytically active sites for ODH on different carbon materials is required to develop highly efficient carbocatalysts, and theoretical calculations are a powerful tool $[63,79,80]$.

Mechanism study is a key point for the comprehensive understanding of the nature of the catalytic process at the molecular level, which is the basis for designing and fabricating highly efficient catalysts. As far as the mechanism for the carbon mediated ODH process is concerned, there are still arguments, and the further study on this issue is essential. Currently, the accepted reaction mechanism of nanocarbons-mediated ODH of hydrocarbons to the corresponding olefins can be illustrated as Fig. 1. The diffusion and chemisorption of hydrocarbons first take place on the ketonic $\mathrm{C}=0$ groups of the carbocatalyst. After the subsequent hydrogen abstraction and the desorption of the olefins, the hydroxyl groups formed are left on the carbocatalyst. Then molecular oxygen diffuses to the prismatic planes like defects and edges with the formed hydroxyl groups, and reoxidizes the catalyst to form surface ketonic $\mathrm{C}=0$ groups, the active sites for the $\mathrm{ODH}$ reaction, and the catalytic cycle is completed after the desorption of water $[4,5,67,72]$. The key points in this ODH process are the diffusion of reactants and olefins, adsorption and activation of reactants, desorption of olefins, and reoxidation of reduced carbocatalyst, which significantly depends on the nature of the active sites and their accessibility as affected by the microstructure and surface chemistry of the carbon material. Therefore, the key content in this review is to describe the state of art in the method and efficiency of microstructure and surface chemistry tuning of carbocatalysts for the dehydrogenation of hydrocarbons to olefins. The aim is to present the concept of microstructure and surface chemistry tuning of carbocatalysts not only for optimizing catalytic performance but also for the fundamental understanding of the structure-performance relationship.

\subsection{DDH reaction}

Compared to the Fe-based catalyst promoted DDH process, the carbocatalyst-mediated DDH process demonstrates energy saving and higher coke resistance. It also eliminates the disadvantages of ODH over carbocatalysts like low selectivity due to overoxidation, damage of catalyst structure by oxygen, and the risk of handling an explosive mixture containing hydrocarbons and oxygen. Besides the above merits, the spent carbocatalysts for DDH can be complete recovered by air exposure, which endows the carbocatalyst-mediated DDH process under oxidant- and steam-free conditions great potential for industrial application. However, the problem of low catalytic activity of current carbocatalysts for the DDH process must be solved before it can be realized.

The fundamental understanding of active sites and mechanism of DDH provide significant guidance for developing highly

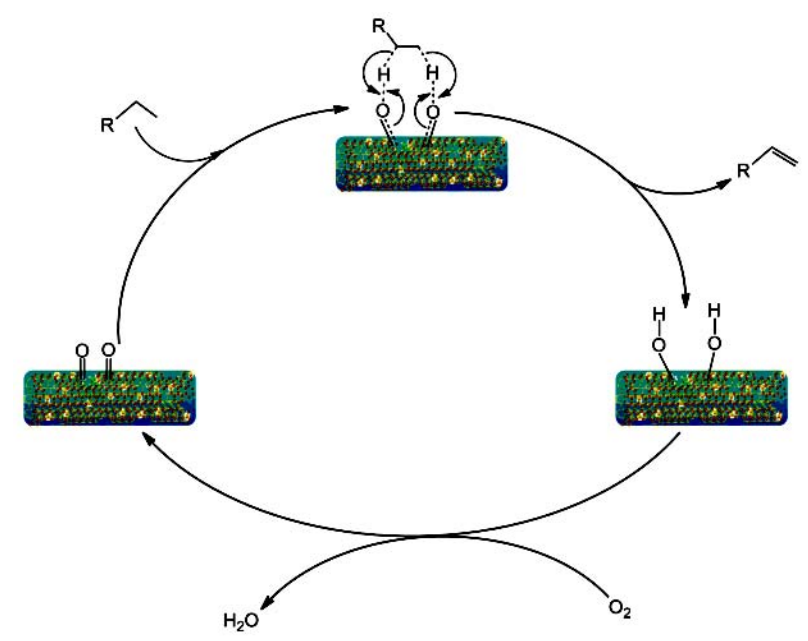

Fig. 1. Schematic of the catalytic ODH reaction mechanism of hydrocarbons to olefins over carbocatalysts. 
efficient carbocatalysts. However, unlike the ODH process, few reports on DDH can be found, especially studies on the mechanism are quite few. Basically, it can be accepted that the ketonic carbonyl groups are active sites to activate the $\mathrm{C}-\mathrm{H}$ bond of hydrocarbons for the DDH reaction [81-91]. Fig. 2 depicts the schematic mechanism of the DDH reaction over carbocatalysts. The catalytic process is similar to that for ODH except for the process of the recovery of the $\mathrm{C}=0$ groups. In the $\mathrm{ODH}$ process, the hydroxyl groups formed from carbonyl groups after attacking the hydrogen in the hydrocarbons can be recovered through a reoxidation process by molecular oxygen. However, in the DDH process, the reaction cycle is closed by the thermal decomposition of $\mathrm{C}-\mathrm{OH}$ to $\mathrm{C}=\mathrm{O}$ and hydrogen, which is thermodynamically favourable at high temperature [47]. Su and co-workers [82] found that, besides the anchored $\mathrm{C}=0$ groups on the defect, edge, and vacancies, the surface structural defects themselves are active sites responsible for the DDH reaction. In our ACM research group, we discovered the promoting effect of $\mathrm{N}$-doping of carbon materials for the DDH of ethylbenzene to styrene, which may be due to the improved nucleophilicity of $\mathrm{C}=\mathrm{O}$ by the increased electron density due to $\mathrm{N}$ introduction into the carbon matrix [83-85,87-89]. Moreover, we developed different approaches to improve the catalytic performance of carbocatalysts for the DDH reaction by the tuning of active sites $[83,84,88]$, and exciting results have been achieved.

The properties of the active sites are essential for the dehydrogenation reaction. At the same time, the accessibility of the active sites to reactants is also quite important. This can be manipulated by tuning the microstructure of the carbocatalyst. The modulation of the microstructure also can tune the active sites, i.e., surface structural defect, edge. The modulation of surface chemistry is a direct and efficient tool for tuning the active sites. Therefore, in the following, we pay attention to the state of the art in modulating the microstructure and surface chemistry of carbocatalysts for dehydrogenation including both $\mathrm{ODH}$ and DDH. How to tune and the activity results of these tuning methods are described, and a concept of microstructure and surface chemistry tuning of carbocatalysts not only for optimizing catalytic performance but also for the fundamental understanding of structure-performance relationship is discussed.

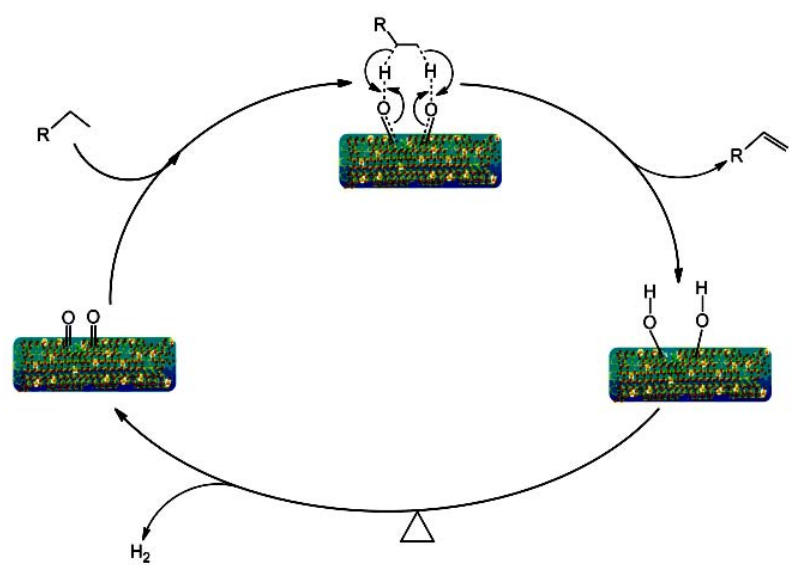

Fig. 2. Schematic mechanism of the catalytic DDH reaction of hydrocarbons to olefins over carbocatalysts.

\section{Modulating microstructures}

Microstructures containing morphology, shape, size, and surface structure of the carbocatalysts significantly affect the accessibility of active sites and the nature of active sites. Therefore the manipulating of microstructure can significantly affect and even control the catalytic performance. Herein we focus the method, effect and inherent essence and law of tuning of the morphology, shape, size, texture, and surface structure in promoting the catalytic performance of carbocatalysts in $\mathrm{ODH}$ and DDH reaction.

\subsection{Morphology, shape, size and texture}

\subsubsection{ODH reaction}

The catalytic performance of carbon materials for the $\mathrm{ODH}$ reaction of hydrocarbons including light alkanes and ethylbenzene is significantly dependent on the morphology and size. In order to improve the catalytic performance of carbocatalysts, a large number of reports focused on tuning the shape, size and texture properties of the existing carbon materials through either post-treatment or the adjustment of synthesis process conditions $[69,74,75,92-106]$, as well as the design and synthesis of carbon materials with new morphologies [66,107-110]. Moreover, although nanocarbons have shown promising performance in the ODH reaction, the fine powder nature of the carbocatalysts is highly detrimental to their use in fixed bed reactors. Fine powders lead to large pressure drops and also to safety in handling. Post-synthesis compaction is not desirable because it changes the chemical properties of nanocarbon materials and inhibits the diffusion of reactants and products inside the compacted material. Therefore, the design and fabrication of macroscopic carbon materials have attracted more attention for the industrial applications [111-114]. Herein, the progress in the tuning of morphology and size of carbon materials for the $\mathrm{ODH}$ reactions is presented. Table 1 is a summary of carbon catalyzed ODH process. The fabrication and tuning of carbocatalysts with different microstructures will be presented.

$\mathrm{Su}$ and coworkers [92] compared the catalytic performance of commercially available carbon nanotube (CNT) and activated carbon (AC) for the ODH of 1-butene to butadiene. It was found that CNT demonstrated more than 10 times higher butadiene formation rate than $\mathrm{AC}$, although the AC had more than 25 times higher surface area than CNT. However, no reason was presented in this report. It was possibly ascribable to the poor stability of AC towards combustion in the ODH process. Anyway, this work showed that the type of carbon materials significantly affects the catalytic performance in the ODH reaction, and CNTs exhibit promising activity for the ODH of 1-tutene. Subsequently they tested the catalytic performance of single walled CNT (SWCNT), multi-walled CNT (MWCNT), and ultra-dispersed diamond (UDD) for the ODH of $n$-butane [93]. Table 2 presents the catalytic performance. The similar conversion of butane in the range of $9 \%-12 \%$ can be observed on the three nanocarbons. However, UDD displayed much superior selectivity towards the selectivity of olefins to CNTs, and $12 \%$, 
Table 1

Summary on the ODH of hydrocarbons over carbocatalysts with different types and microstructures.

\begin{tabular}{|c|c|c|c|}
\hline Reactant & Carbocatalyst & Comment & Ref. \\
\hline Ethylbenzene & CNF, Soot, Gr. & Soot has higher initial activity, CNF exhibits higher steady state yield & [67] \\
\hline Ethylbenzene & OLC, CNF, Gr. & OLC shows highest steady-state styrene yield (62\%) & [95] \\
\hline Ethylbenzene & CMK-3, CNT, and CNF & Due to good mass transport, CMK-3 shows better catalytic performance & {$[69,97]$} \\
\hline Ethylbenzene & AC, CNT, ND & CNT shows better activity and stability for ODH of ethylbenzene & {$[72,79]$} \\
\hline Ethylbenzene & r-PGO, o-CNT, and Gr. & r-PGO exhibits best performance with $65 \%$ of EB conversion and $93 \%$ of styrene selectivity & {$[100]$} \\
\hline Ethylbenzene & F-CNF, T-CNF & Fishbone-like CNF (F-CNF) has shown best catalytic performance & {$[102]$} \\
\hline Ethylbenzene & Hierarchical porous carbon & Owing to hierarchical pores, high surface area and pore volume & [107] \\
\hline Ethylbenzene & CFoam 1500 & Higher catalytic performance than reported MWCNT, OLC, CNF/Gr. & [108] \\
\hline Ethylbenzene & Honeycomb-like carbon & The unique morphology and porosity resulting in high catalytic performance & [109] \\
\hline Ethylbenzene & CNF/Gr.-felt & The immobilized CNFs exhibits great catalytic stability & {$[114]$} \\
\hline Ethylbenzene & CNT/SiC monolith & $\begin{array}{l}\text { Good mechanical and thermal properties, to avoid pressure drop and hot spots, exhibits } \\
\text { high activity and stability }\end{array}$ & {$[111]$} \\
\hline Ethylbenzene & Millimeter-scale CNTs sphere & $\begin{array}{l}\text { The monolithic CNT sphere higher selectivity and similar activity to CNTs, as well as } \\
\text { avoid mechanical post-treatment of CNT powder during compacting process }\end{array}$ & {$[113]$} \\
\hline 1-Butene & CNT & It shows 10 times higher butadiene formation rate than $\mathrm{AC}$ & [92] \\
\hline$n$-Butane & SWCNT, MWCNT, UDD & The UDD shows similar activity but much higher selectivity for 1-butene formation & [93] \\
\hline iso-Butane & GMC & $\begin{array}{l}\text { The graphitic mesoporous carbon with fullerene-like cage exhibits obvious activity while } \\
\text { the cage was opened. }\end{array}$ & {$[106]$} \\
\hline Propane & ND derived carbon & $\begin{array}{l}\text { The catalytic activity gradually rises along with the extending time on stream, suggesting } \\
\text { the in situ formation of active sites on surface defects. }\end{array}$ & [76] \\
\hline Propane & F-CNF, T-CNF & $\begin{array}{l}\text { F-CNF exhibits twice higher activity for ODH of propane than T-CNF, and also higher } \\
\text { selectivity }\end{array}$ & {$[101]$} \\
\hline
\end{tabular}

Gr.-graphite.

$20 \%$, and $56 \%$ of selectivity towards olefins can be obtained by using SWCNT, MWCNT, and UDD, respectively, as catalyst. The UDD catalyst exhibited much higher inhibiting effect on over-oxidation of hydrocarbons, ascribed to the reduced amount of electrophilic oxygen species on UDD in comparison with that on SWCNT or MWCNT. Interestingly, the concentrations of 1-butene and 2-butene were much higher than that of butadiene over UDD. However, these were much lower over SWCNT or MWCNT, with the further dehydrogenation significantly hindered. Then they tested the catalytic performance of nanofilament (CNF), soot and graphite for the ODH of ethylbenzene [67]. Fig. 3 displays the styrene yield over the three carbon materials with the time on stream. The soot showed much higher initial activity for styrene formation in comparison to the other two. However, the activity rapidly dropped with time on stream. The CNF and graphite exhibited outstanding stability, ascribed to their much better stability towards combustion. The activity rose initially over CNF and graphite with time on stream, possibly resulting from the build-up of surface oxygen groups as active sites. 85\%, 80\%, and $65 \%$ of selectivity over CNF, graphite, and soot, respectively, were obtained. CNF displayed the highest styrene yield among the three samples. The combination of high activity, selectivity and stability with the recently reported cheap synthesis of CNF endows it a promising future for styrene produc-

Table 2

Catalytic performance of nanocarbons [93].

\begin{tabular}{lccccccc}
\hline \multirow{2}{*}{ Catalyst } & $\begin{array}{c}\text { Conversion } \\
\end{array}$ & \multicolumn{4}{c}{ Selectivity (\%) } & \multicolumn{3}{r}{ Yield } \\
\cline { 3 - 7 } & 1-Butene & 2-Butene & Butadiene & $\mathrm{CO}^{2}$ & $\mathrm{CO}_{2}$ & $(\%)$ \\
\hline SWCNT & 9 & 2 & 1 & 10 & 8 & 80 & 1 \\
MWCNT & 12 & 3 & 1 & 16 & 8 & 72 & 2 \\
UDD & 11 & 33 & 9 & 15 & 15 & 28 & 6
\end{tabular}

All data were collected after $10 \mathrm{~h}$ time on stream with stable catalytic performance. tion by the metal-free carbocatalyst-mediated ODH reaction of ethylbenzene.

They further compared onion-like carbon (OLC), graphite (Gr.), carbon nanofilament (CNF) as catalyst and the industrially used K-Fe catalysts for the ODH of ethylbenzene to styrene under the same reaction conditions [95]. Fig. 4 presents the results. The OLC catalyst demonstrated a minor initial catalytic activity rising to $92 \%$ after an initial activation stage of $120 \mathrm{~min}$ on stream. The $68 \%$ steady state styrene selectivity allowed $62 \%$ of high styrene yield to be obtained. Moreover, the OLC demonstrated a higher steady state styrene yield than the others and even more than the industrially used K-Fe catalyst. The results showed that great potential for catalytic applications lies in non-promoted nanocarbon materials if the microstructure can be tailored to support the optimum distribution of electron-donating and $\mathrm{C}-\mathrm{H}$ activating functions. The chemical

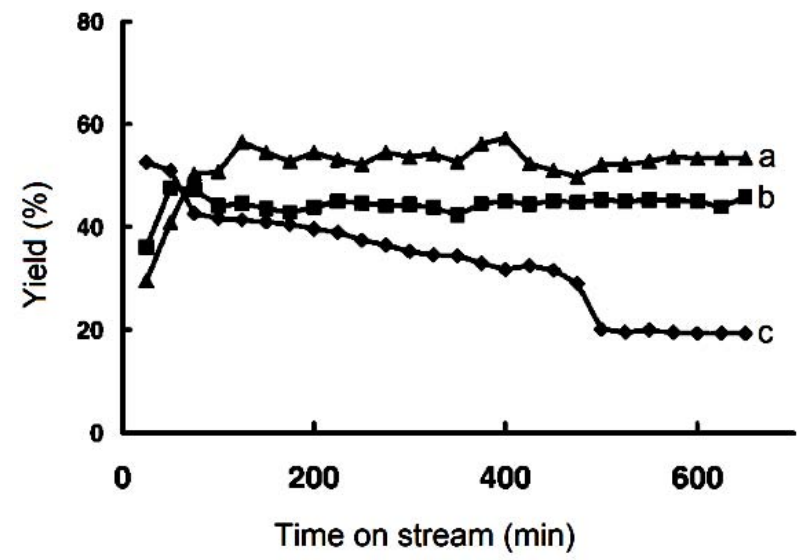

Fig. 3. Styrene yield through ODH of ethylbenzene over nanofilament (a), graphite (b) and soot (c) as a function of time on stream at $820 \mathrm{~K}$. Reproduced with permission from Ref. [67]. Copyright 2001, Wiley-VCH. 


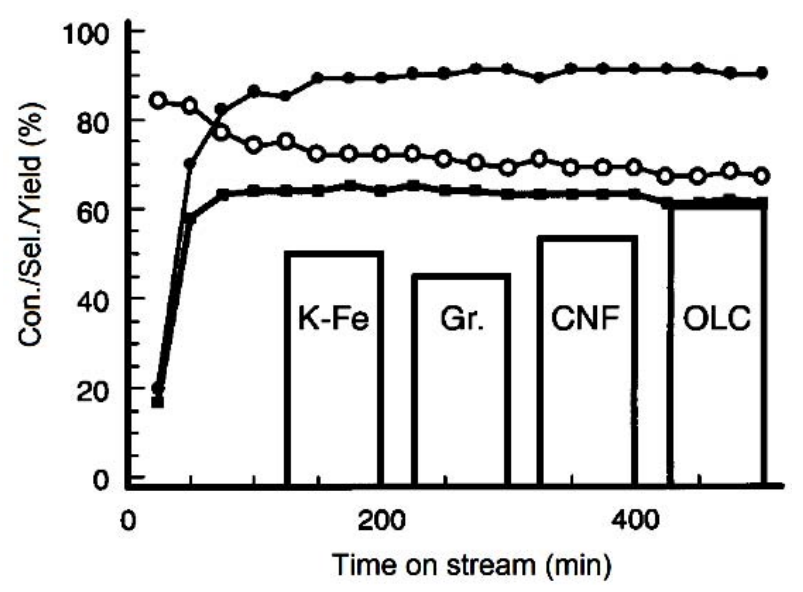

Fig. 4. Catalytic performance including conversion $(\bullet)$, selectivity $(O)$, and styrene yield ( $\square$ ) of onion like carbon (OLC) for ODH of ethylbenzene as well as the steady state styrene yields over OLC, graphite (Gr.), carbon nanofilament (CNF) and industrial K-Fe catalyst (Column graphs). Reproduced with permission from Ref. [95]. Copyright 2002, Wiley-VCH.

simplicity of carbon and the unique self-cleaning behaviour that deactivated surfaces gasify themselves in the ODH process not only makes carbon species well-suited model systems but also allows realistic expectations of an industrial application in heterogeneous catalysis.

Graphitic nanocarbons like carbon nanofilaments, onion-like carbons and carbon nanotubes have been established as highly active catalysts for the ODH reaction, which was ascribed to surface defects and the $s p^{2}$ character of electrons in the basal planes. It was accepted that it is difficult to form oxygen species on perfect graphitic layers, and therefore a perfect graphitic carbon is not active for the ODH reaction. However, there are many defects, edges, and vacancies formed on graphitic planes. These defects, edges, and vacancies allow oxygen species to anchor on them, to perform as active sites to promote the ODH reaction. However, interestingly, it was found that the amorphous mesoporous carbon CMK-3 exhibited a much superior catalytic performance in the ODH of ethylbenzene to styrene to the reported carbon nanotubes and carbon nanofibers under the same reaction conditions [97]. From the XPS and IR characterization experiments on CMK-3 before and after reaction, it was confirmed that the reaction mechanism was the same as that when the nanocarbons were used. However, CMK-3 acts in the reaction quite differently from nanocarbons. While no coke formation was observed when carbon nanotubes were used for this reaction, CMK-3 plays a "support" role for active coke that is formed during the ODH of ethyl benzene. The results gave a further demonstration that the unusual stability of CMK-3 was related to its unique structure: the larger but well-ordered porosity of mesoporous carbon is advantageous for mass transport and good thermal stability. The specific surface area of the spent mesoporous carbon was still as high as $211 \mathrm{~m}^{2} \mathrm{~g}^{-1}$, while the specific surface area of activated carbon typically decreased from above $1000 \mathrm{~m}^{2} \mathrm{~g}^{-1}$ down to less than $80 \mathrm{~m}^{2} \mathrm{~g}^{-1}$ after $24 \mathrm{~h}$ of reaction. Moreover, using the acid-catalyzed precipitation method of polycondensation of furfuryl alcohol to poly(furfuryl alcohol) (PFA) as carbon precursor, in the pores of SBA-15, Kuśtrowski and coworkers [69] fabricated a series of polymer-derived carbon CMK-3 carbon replica with different textural properties by adjusting the mass ratio of PFA to SBA-15. A notably different catalytic performance in ODH of ethylbenzene was obtained, which resulted from its very accessible pore system, besides the difference in oxygen-containing functional groups on the expanded carbon surface.

The catalytic performance of activated carbon (AC), nanodiamond (ND) and the different carbon nanotubes (CNT-1, CNT-2, and CNT-3) with different length and wall thickness for the $\mathrm{ODH}$ reaction of ethylbenzene was investigated in a fixed bed reactor [72,79]. In Fig. 5, except for AC, after a short induction period, each nanocarbon can stably catalyze the ODH reaction of ethylbenzene for styrene formation over $1500 \mathrm{~min}$. The steady state selectivity obtained was as high as $95 \%$ which is an indicator of successful depressing of over-oxidation. The serious deactivation of AC can be clearly seen, and after the
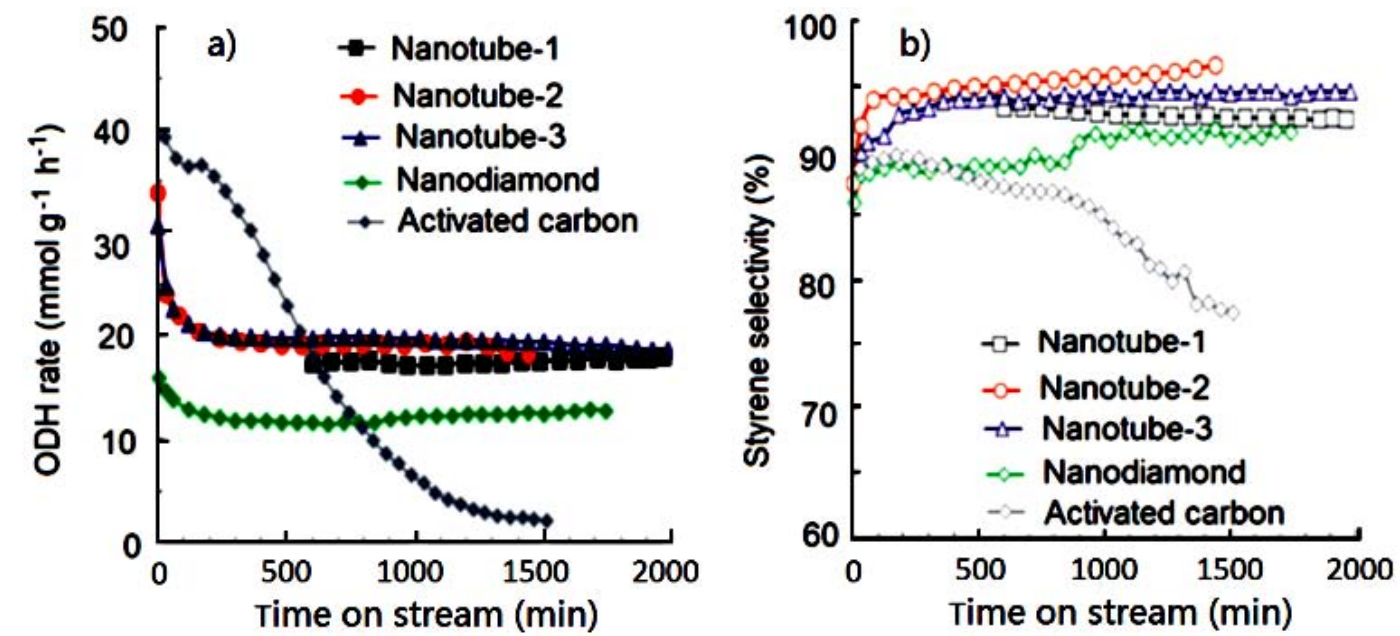

Fig. 5. ODH rate (a) and styrene selectivity (b) of activated carbon, nanodiamond and the diverse carbon nanotubes with different length and wall thickness (Nanotube-1: 3-14 $\mu \mathrm{m}$ length and $15 \pm 10 \mathrm{~nm}$, Nanotube-2: $1-10 \mu \mathrm{m}$ length and $8 \pm 4 \mathrm{~nm}$, and Nanotube- $-3: 0.1-1 \mu \mathrm{m}$ length and $7 \pm 3 \mathrm{~nm}$ ) for $\mathrm{ODH}$ reaction of ethylbenzene at $450^{\circ} \mathrm{C}$. Reproduced with permission from Ref. [72]. Copyright 2007, Wiley-VCH. 
time on stream reached $1600 \mathrm{~min}$, the $\mathrm{ODH}$ rate was only $5 \%$ of the initiate rate with a $76 \%$ low selectivity. The higher than $100 \%$ of the carbon balance and the high $\mathrm{CO}_{2}$ yield revealed that the deactivation of $\mathrm{AC}$ in $\mathrm{ODH}$ mainly came from $\mathrm{AC}$ combustion. The CNTs demonstrated superior catalytic performance to ND, ascribed to the different morphology and electronic properties. From this work, the different size and morphologies of the different CNTs lead to the difference in activation energy and ODH rate. Pereira and coworkers [99] further confirmed that the CNTs had the advantage of their high stability over activated carbon under oxidative conditions.

The morphology effect has been further confirmed by the following example. Graphene, as a star material, has attracted extensive attention in many fields including catalysis. Su and co-workers [100] first explored the application of graphene in the ODH of ethylbenzene (EB) for styrene (ST) production. The catalytic performance of reduced porous graphene oxide ( $\mathrm{rGO})$, routinely reduced graphene oxide (rGO), oxidized carbon nanotube (oCNT) and graphite powder were tested. The results are displayed in Fig. 6. rPGO exhibited the best catalytic performance with 65\% EB conversion and 93\% ST selectivity ( $9.27 \mathrm{mmol} \mathrm{g}^{-1} \mathrm{~h}^{-1}$ ST formation rate) compared with the other carbon materials. The special structure of $\mathrm{rPGO}$ provides more anchor sites for oxygen-containing functional groups on the defects, and the unpaired electrons at the edges of defects can attract and enhance the activation of molecular oxygen in an oxidizing atmosphere.

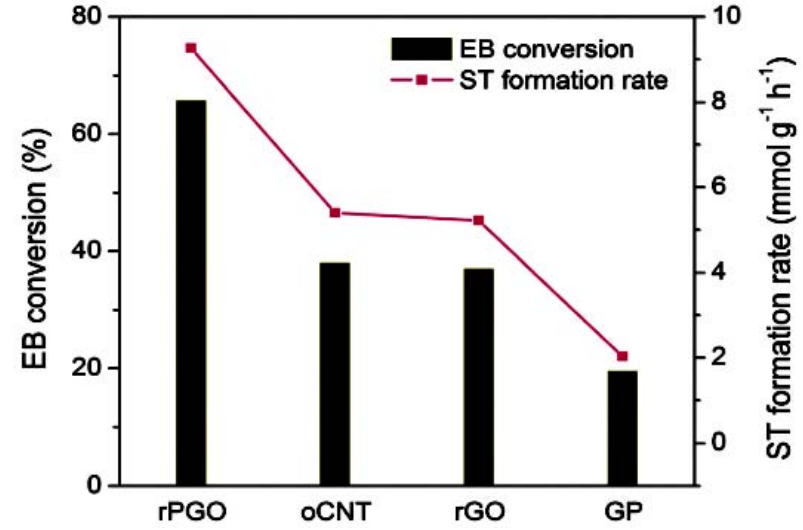

Fig. 6. Catalytic performance of different carbon materials during the $\mathrm{ODH}$ of EB, data obtained from $30 \mathrm{~h}$ on stream. Reproduced with permission from Ref. [100]. Copyright 2015, RSC.

The evolution and catalytic properties of ND derived carbons with different $s p^{2} / s p^{3}$ ratio by annealing at the temperatures of 1000, 1300 and $1500{ }^{\circ} \mathrm{C}$ were studied (Fig. 7) [76]. Through the annealing treatment, the morphology of ND can be tuned. An increased annealing temperature leads to more graphitic layers enclosed on the diamond core. On annealing at $1500{ }^{\circ} \mathrm{C}$, the ND particles were transformed into spherical carbon onions with a highly ordered $s p^{2}$ hybridized graphitic structure and almost oxygen-free surface. It was also found that the surface area and pore volume monotonically increased as
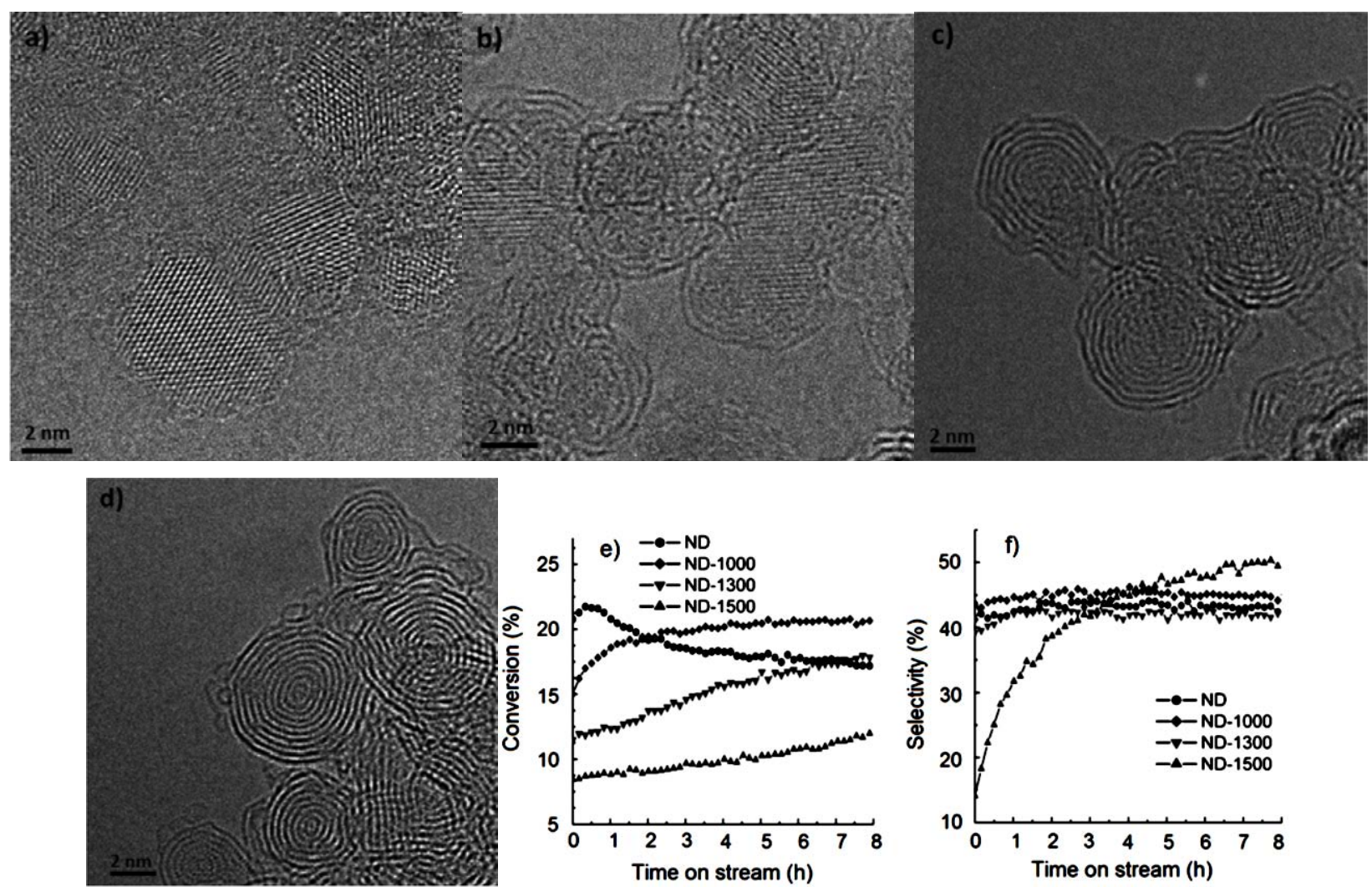

Fig. 7. TEM images of ND (a), ND-1000 (b), ND-1300 (c), and ND-1500 (d), as well as catalytic performance including EB conversion (e) and ST selectivity (f) of ND-derived carbon materials in ODH of EB as a function a time on stream. Reproduced with permission from Ref. [76]. Copyright 2014, Wiley-VCH. 
the annealing temperature rose from 1000 to $1500{ }^{\circ} \mathrm{C}$. For the fresh ND catalyst, a clear decrease in propane conversion can be observed in the initial $4 \mathrm{~h}$ of the reaction (Fig. $7(\mathrm{e})$ ), which was likely related to the removal of active sites present on the amorphous carbon surface. In comparison with the parent ND, there was a gradual increase in propane conversion for all of the annealed catalysts, suggesting that the active sites were in situ generated on the surface defects of graphitic carbon under the ODH reaction conditions. For the ND samples derived with different annealing temperatures, the required activation process was prolonged as the annealing temperature rose, showing that the generation rate of active sites was inversely proportional to the degree of defects of the graphitic shell. Similarly, there was also a gradual increase in propene selectivity in the initial stage (Fig. 7(f)). A remarkably increased selectivity to propene from $14 \%$ to $50 \%$ was found on ND-1500, which implied that the active species with highly selective alkane activation were formed on the graphitic onion-like carbon structure during reaction. This finding further showed that catalytic active sites and catalytic performance were significantly dependent on the microstructure of the carbocatalysts.

Nanofiber (CNF) has exhibited good potential for the ODH of hydrocarbons to olefins. However, the further improvement in selectivity and stability for ODH is required. It has been established that the catalytic performance of solid catalysts is significantly dependent on their microstructure. Therefore, microstructure tuning has attracted great attention. The bottom up approach is an efficient method to tune the microstructure. Dai and coworkers [101] prepared fishbone carbon nanofiber (F-CNF) and tubular carbon nanofiber (T-CNF) (Fig. 8) by using a CVD method with alumina supported Ni-Fe alloy and Ni catalysts, respectively, and investigated the catalytic performance in the ODH of propane and the structure-performance relationship. The different structural characteristics of F-CNF and T-CNF led to a difference in surface chemistry including the type, amount, and distribution of oxygen functional groups, which in turn resulted in a difference in catalytic performance. F-CNF demonstrated more than twice higher propane conversion and also higher selectivity in comparison to T-CNF, which further confirmed the role of the microstructure in affecting the catalytic performance of carbocatalysts in the ODH reaction. Furthermore, T-CNF suffered from post-treatment by nitric acid, and the as-treated T-CNF (T-CNF-ox) exhibited significantly increased ODH activity and selectivity towards propene.

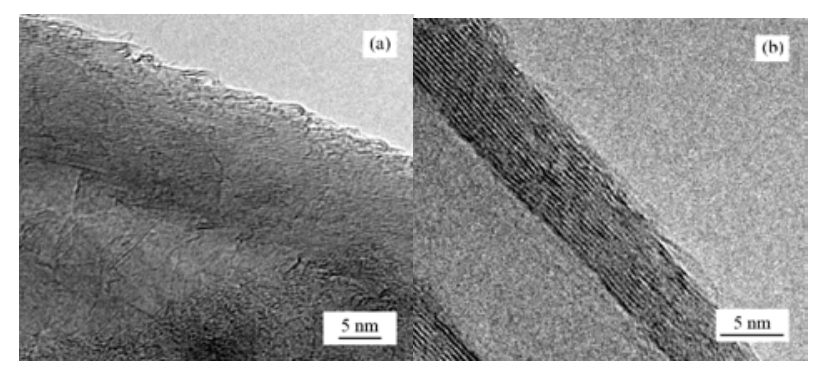

Fig. 8. TEM images of fishbone carbon nanofiber (a) and tubular carbon nanofiber (b) prepared by CVD method using $\mathrm{Al}_{2} \mathrm{O}_{3}$ supported $\mathrm{Ni}-\mathrm{Fe}$ alloy and Ni catalysts, respectively [101].
In order to identify the role of the porous texture of CNFs in affecting the ODH catalytic performance, Figueiredo and coworkers [102] made some fruitful researches. Diverse CNFs with different texture but similar surface chemistry were used to investigate the texture effect on the catalytic performance in ODH of ethylbenzene to styrene. Reaction results demonstrated that these CNFs exhibited much different conversion of ethylbenzene and selectivity towards styrene, $\mathrm{CO}_{2}$ and $\mathrm{CO}$. The observed catalytic performances were interpreted exclusively in terms of their textural properties. Analysis of the catalytic results highlighted common trends. In particular, the fibers with an average micropore width larger than $1.2 \mathrm{~nm}$ were found to be the best catalysts for this ODH reaction. The rational design of the CNF catalysts for ODH has been studied. CNFs with systematically varied graphitic platelet orientations were used as a model system for the rational catalyst design, with respect to the nature of the carbon nanofiber and the amount of basic groups, crystallinity, and the ratio between the prismatic area and the basal plane area. From the reaction results, no clear evidence was found for the ODH catalytic performance being related to the surface area and graphitization degree of CNFs. However, the ratio of the prismatic surface area to the basal area was identified as the most important parameter for rational catalyst design, which significantly affects the catalytic performance in the ODH reaction. The fish-bone CNF catalysts were the best catalyst in their investigated samples, which was ascribed to the large number of basic edge groups, and optimum ratio between the prismatic and basal plane area. This resulted in a delicate balance in the redox catalytic cycle. As a consequence, the formation of $\mathrm{CO}_{2}$ was reduced.

The above research gave a clear view that the tuning of microstructure of carbon materials through the bottom-up approach or post treatment could efficiently change their catalytic performance in ODH reaction. Therefore, many researchers began to be interested in designing and fabricating carbon materials with novel morphologies and in tuning the microstructure by the post-treatment for the ODH reaction. The advances in this subject are reviewed as follows [106-114]. Liang and coworkers [106] reported a facile preparation of novel graphitic mesoporous carbon (GMC) with fullerene-like cages by a soft-template approach, which can be opened and closed through simple thermal treatment (Fig. 9 (A)-(D), the as-synthesized sample was named SC01; the sample identified as SC02 was prepared by the oxidation of SC01 in air at $500{ }^{\circ} \mathrm{C}$ for $15 \mathrm{~h}$; SC02 was further heat-treated in He for $1 \mathrm{~h}$ at $1600{ }^{\circ} \mathrm{C}$ and denoted as SC03; SC04 was obtained by heat treatment of SC03 to $2600{ }^{\circ} \mathrm{C}$ in He). This glassy carbon with enclosed fullerene-like cages of 2-3 nm was synthesized by a soft-template approach that created open mesopores of $7 \mathrm{~nm}$. The open mesopores provided access to the fullerene-like cages, which can be opened and closed by heat treatment in air and inert gas at different temperatures. The GMC exhibited obvious catalytic activity in the $\mathrm{ODH}$ of iso-butane when the fullerene-like cavities were open, regardless of the existence of surface oxygen-containing groups. The GMC catalysts were deactivated after the fullerene-like cavities were closed by thermal treatment. Therefore, the catalytic activity was related to the open- 

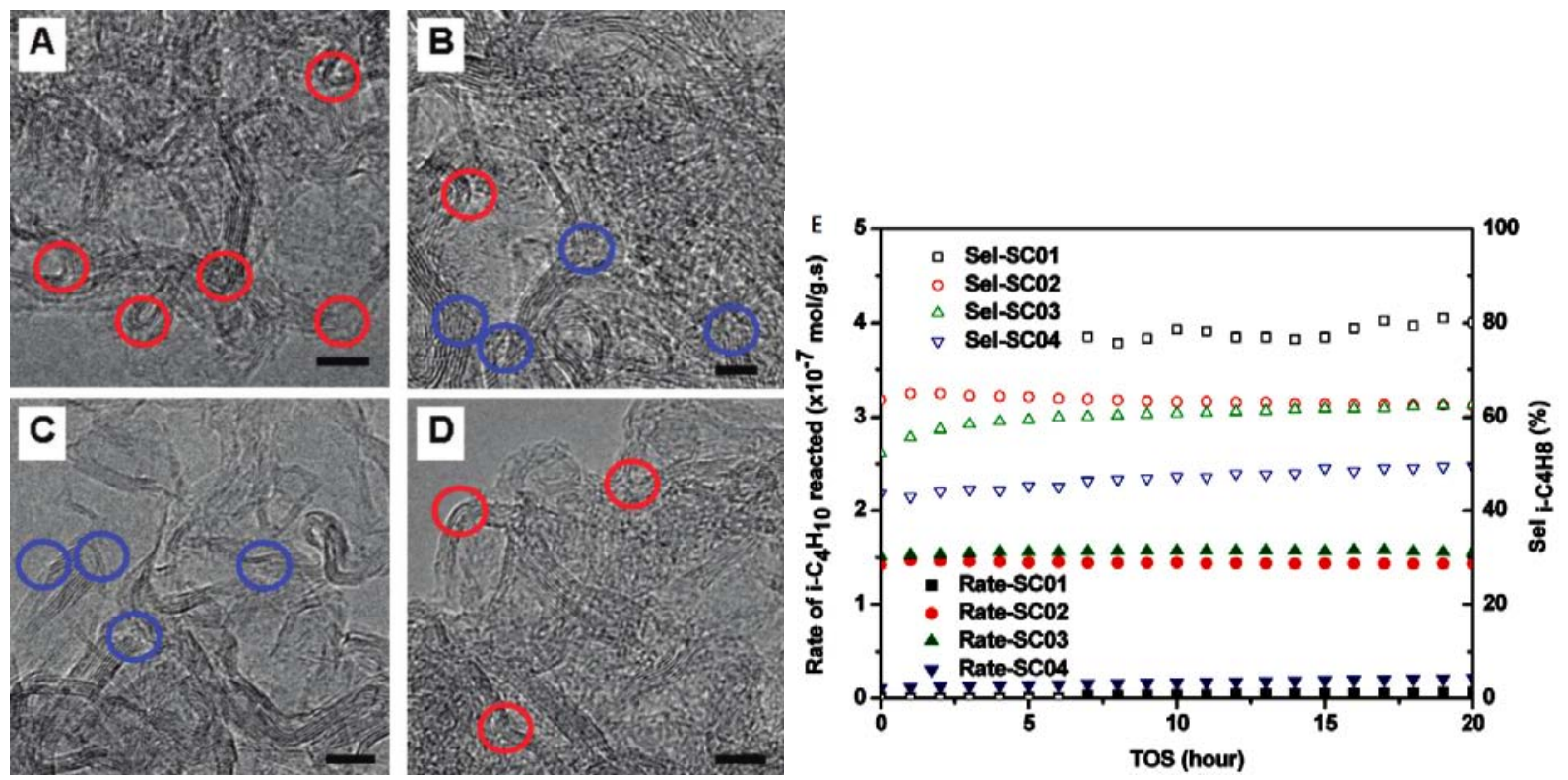

Fig. 9. HRTEM images of SC01 (A), SC02 (B), SC03 (C), and SC04 (D) as well as their catalytic performance in ODH of iso-butane to iso-butene (E). Red circles indicate the "loop back structures", whereas blue circles indicate the open edge sites of the graphitic carbons (scale bars represent $5 \mathrm{~nm}$ ). Reproduced with permission from Ref. [106]. Copyright 2009, ACS.

ness of the fullerene-like cavities. The open cavities have accessible graphitic planes with open edges. These open edges were most likely the catalytic active sites of this carbon catalyst in the $\mathrm{ODH}$ reactions.

Xiao and coworkers [107] successfully synthesized pre-shaped hierarchical porous carbon (HPC) spheres by a facile anion exchange route, in which an industrial polymeric anion-exchange resin with a hierarchical pore structure was used as the carbon precursor. Fig. 10 presents the SEM image and BET results of HPC. The as-synthesized HPC spheres were tested as catalyst for the oxidative dehydrogenation of ethylbenzene to styrene. The as-synthesized HPC spheres possessed an abundant hierarchical porosity, high surface area, and high pore volume as well as an oxygen-rich surface, which resulted in an active and stable pre-shaped catalyst for the ODH of EB.

The previously reported results showed that the catalytic performance of nanocarbons was strongly dependent on their morphology. Recently, Qiu and co-workers [108] present a further illustration. They developed a simple one-step method for fabricating CFoams with the cell walls made of hollow carbon nanocapsule (CNCs) with good crystallinity (CNC/CFoam1500). The open cells of the CFoams were $500 \mu \mathrm{m}$ in diameter with mesoporous cell walls (Fig. 11). The macroporous frame would guarantee the improved hydrodynamic performance and rapid transport of species inside the monolith while the mesoporous structure would provide sufficient and accessible active sites for the ODE reaction. As a result, the CNC/CFoam1500 exhibited higher reaction rate and selectivity than the reported MWCNT, OLC, and CNF/graphitic felt for the $\mathrm{ODH}$ of ethylbenzene to styrene. Moreover, the honeycomb-like macrostructured carbon with well-defined microporosity (Fig. 12) was prepared by the microwave popping of maize followed by thermal carbonization. The as-obtained carbon material exhibited promising catalytic activity for ODH of ethylbenzene to styrene [109], ascribed to its unique morphology and porosity.

In the references, CNT and CNF have exhibited outstanding
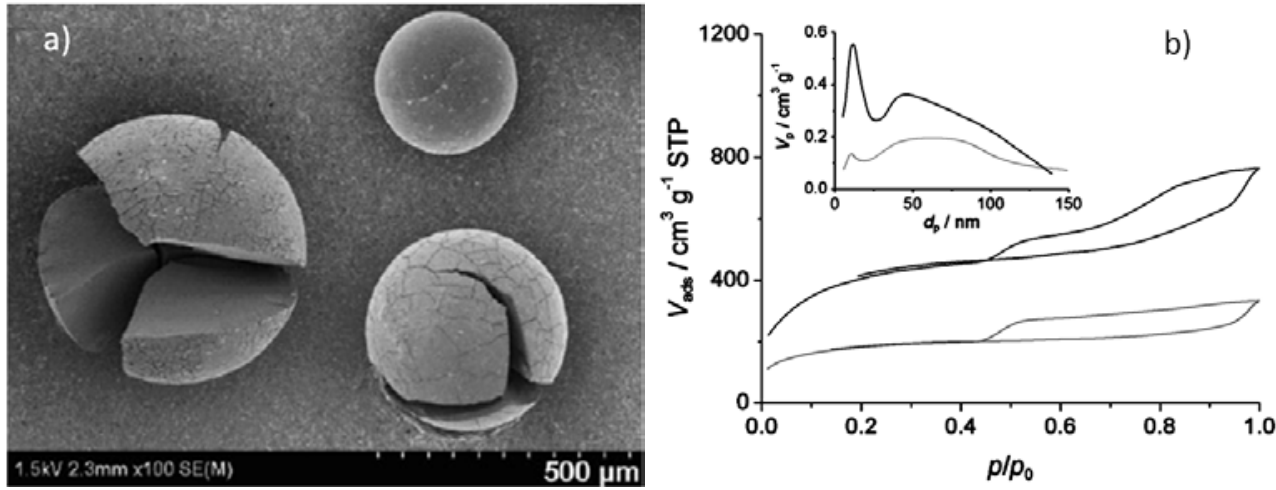

Fig. 10. SEM images (a) and $\mathrm{N}_{2}$ adsorption isotherms and pore size distribution (b) of HPC spheres. Reproduced with permission from Ref. [107]. Copyright 2012, Wiley-VCH. 

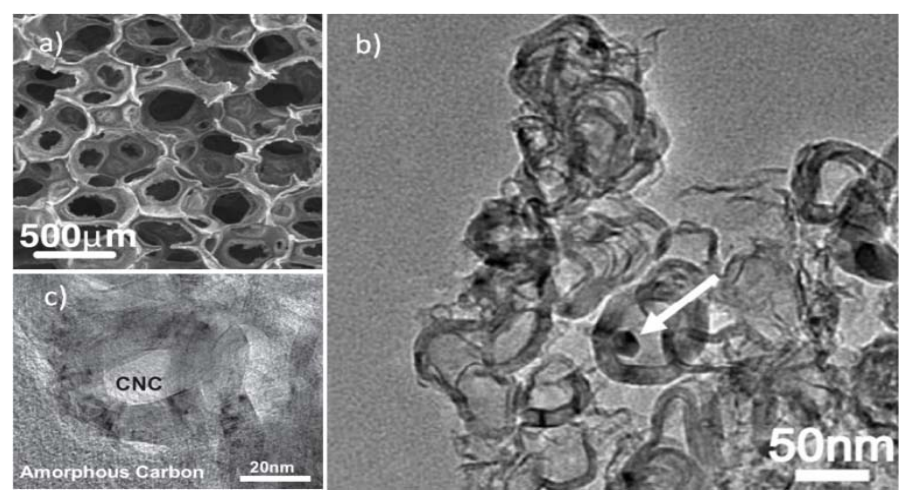

Fig. 11. SEM image (a) and TEM image (b) of CNC/CFoam1500, and the TEM image (c) of a CNC embedded into amorphous carbon in the CNC/CFoam1500. Reproduced with permission from Ref. [108]. Copyright 2013, Elsevier.

catalytic performance in the $\mathrm{ODH}$ of hydrocarbons to olefins. However, these CNT and CNF powders tend to agglomerate and are difficult to filter in slurry phase operation. These powders cannot be directly used in fixed bed reactors owing to a high pressure drop and safety handling issue. Therefore, it is necessary to form CNT and CNF powers into larger objects. The method of the compaction of powdered nanocarbons usually inhibits the access of reactants to its active sites and can destroy individual carbon structures during the compacting process. The immobilization of nanocarbons powders on supports can be a practical approach to address these problems. Recently, the macroscopic nanocarbon monolith has attracted interest.

Li and coworkers [114] synthesized a carbon nanofiber/graphite-felt composite with a desirable shape and size by the method of catalytic chemical vapor deposition (CCVD) via the growth of CNFs on the surface of the nickel impregnated graphite microfibers of the felt. Fig. 13 displays the SEM images of the graphite fibers and the synthesized composites with different morphologies and mass ratio of CNFS to felt in the composites by adjusting the growth time. The distinct mesoporous character, a large external surface area and high mechanical strength make the CNF/graphite-felt composites attractive as a catalyst for the ODH of ethylbenzene to styrene. Moreover, a CNT/SiC monolith was also successfully prepared through the immobilization of CNTs onto a SiC foam [111]. The synthesized CNT/SiC monolith featured a uniform CNT layer on SiC foam. The monolith with its good mechanical and thermal properties avoid the issues of pressure drop and hot spot during the catalytic reaction. It showed higher selectivity, butadiene formation rate, and stability than powdered CNT. Also the CNT/SiC mono-

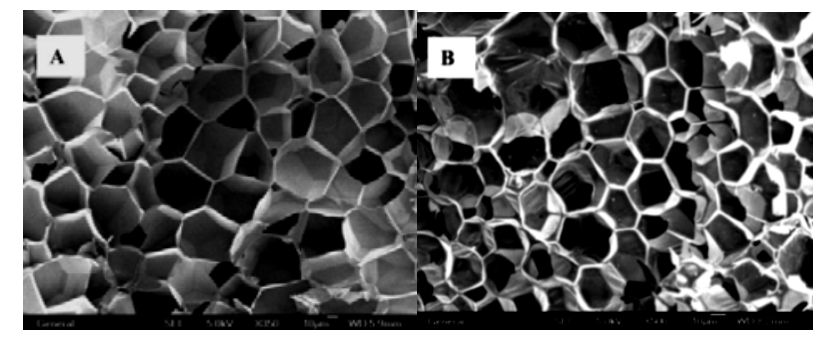

Fig. 12. SEM images of popcorn (A) and popcarbon (B). Reproduced with permission from Ref. [109]. Copyright 2007, ACS. lith has potential in liquid phase reactions, owing to its good mechanical strength and easy filtration.

Xiao et al. [113] have made a smart design. They explored a simple and direct method to produce monolithic CNTs as mm-scale spheres (Fig. 14(a)), featuring an integral continuity in the structure from the microscopic to the macroscopic scale. The ion-exchanged resin spheres were calcined at $800{ }^{\circ} \mathrm{C}$ in a flow of $\mathrm{N}_{2}$ or under vacuum, after which the average diameter decreased from 0.77 to $0.49 \mathrm{~mm}$, while the bulk density increased from 0.55 to $0.91 \mathrm{~g} \mathrm{~m} / \mathrm{L}$. From Fig. 14(b), the twisted nanotubes constructed a monolith which maintained a spherical shape. As shown in Fig. 14(c), the synthesized CNT monolith showed outstanding performance at $400{ }^{\circ} \mathrm{C}$. Its activity was similar to that of commercial CNT powder, providing almost the same styrene yield, while the monolith displayed a superior selectivity of $90 \%$. In comparison, the pure CNT powder gives a value of only $68 \%$. The higher selectivity can be related to the advantage of the monolithic structure in allowing the fast diffusion of the styrene product. This approach exhibited a potential for industrial application of carbocatalysts in styrene produc-
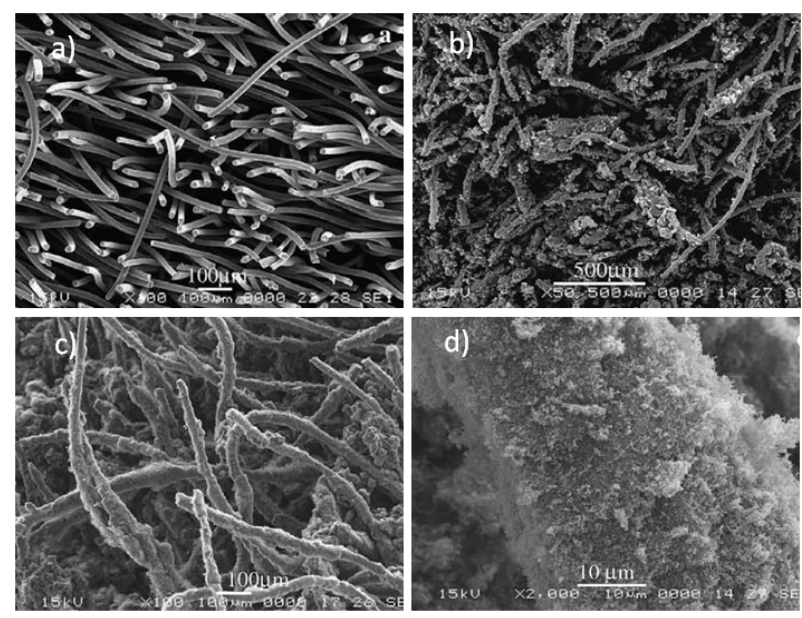

Fig. 13. Typical SEM images of graphite fibers and carbon nanofibers illustrating the evolution of $\mathrm{CNF} /$ graphite-felt composite synthesis: (a) graphite fibers of felt; (b) graphite fibers covered by carbon filaments having been grown for $3 \mathrm{~h}$; (c) graphite fibers covered by filaments with carbon agglomerates within felt after reaction for $8 \mathrm{~h}$; (d) fleecy filaments grown on the surface of graphite fibers. Reproduced with permission from Ref. [114]. Copyright 2006, Elsevier. 
a)
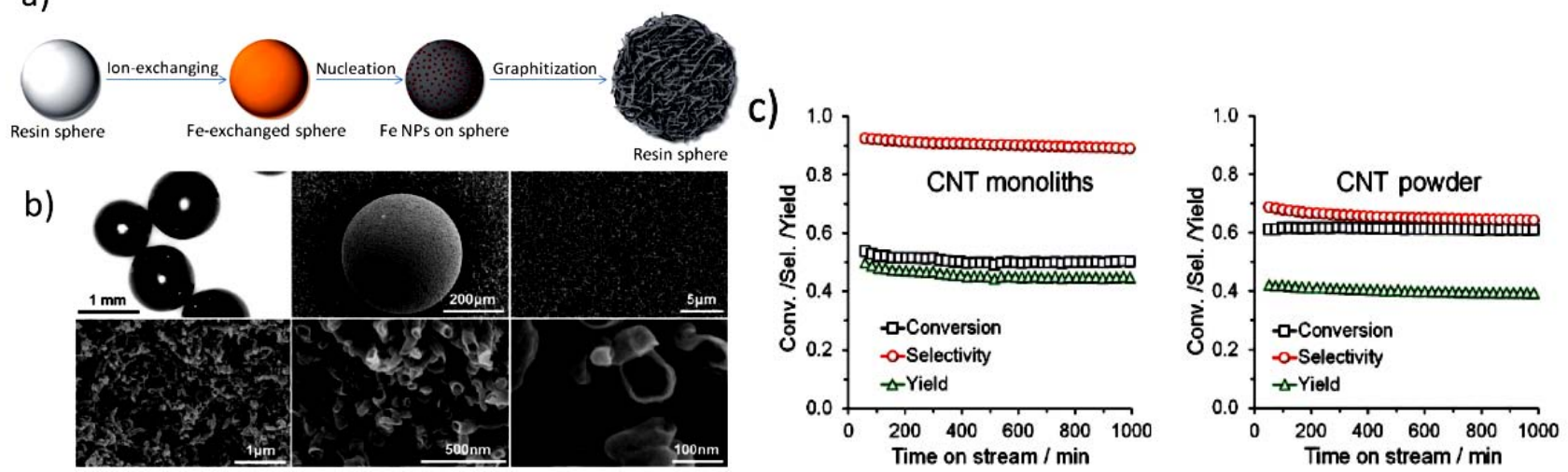

Fig. 14. Schematic representation for synthesis (a), optical microscopy and SEM images at various magnification scales (b), and catalytic performance in ODH of ethylbenzene to styrene of the as-prepared CNT monolith (c). Reproduced with permission from Ref. [113]. Copyright 2012, Wiley-VCH.

tion through the $\mathrm{ODH}$ of ethylbenzene.

Besides use in ODH, the morphology, shape, size, and texture of nanocarbons strongly affected their catalytic performance in the DDH reaction of hydrocarbons to olefins. The effect of the tuning of microstructure on the catalytic performance in DDH is summarized as follows.

\subsubsection{DDH reaction}

Different from $\mathrm{ODH}$, few reports on the carbocatalyst-mediated DDH reaction can be found. The oxidant- and steam-free DDH reaction over nanocarbon catalysts is an alternative for olefin production with clean, safety and energy-saving features. The DDH of ethylbenzene was first reported by Su and coworkers [47] by employing nanodiamond (ND) as an efficient metal-free carbocatalyst, which facilitated related studies on developing novel and efficient carbocatalysts for this reaction. In order to develop excellent DDH catalysts, both the bottom up strategy and post-treatment have been employed to tailor the morphology, shape and size. Herein the advance in the tuning of morphology, shape and size of carbocatalysts for DDH of hydrocarbons are summarized and listed in Table 3. Mesoporous carbon, mesoporous carbon nitride, CNT, N-doped $\mathrm{CNT}$, N-doped ND, and their hybrids as well as some macroscopic carbon materials have been prepared and used in DDH reactions.

Yuan and co-workers [81] prepared ordered mesoporous carbons OMC-1 and OMC-2 with different pore structural systems by a low temperature autoclaving method based on the $\mathrm{HCl}$ catalyzed organic-organic self-assembly method using different molar ratio of formaldehyde to resorcinol and autoclaving time. OMC-1 has a well-ordered hexagonal mesostructure observed in TEM images. However, OMC-2 also showed periodic arranged pore structures with neighbouring channels interconnected. The classic CMK-3 was also synthesized for comparison. The catalytic performance of the three mesoporous carbons for the DDH of propane to propene was tested. It

Table 3

Catalytic tests using $\mathrm{HTC}-\mathrm{HSO}_{3}$ heterogeneous catalyst as well as pure sulphuric acid homogenous catalysts.

\begin{tabular}{|c|c|c|c|}
\hline Reactant & Carbocatalyst & Performance & Ref. \\
\hline Propane & OMC-1, OMC-2, CMK-3 & OCM-1 and OCM-2 show much higher propylene yield than CMK-3 & [81] \\
\hline Propane & COMC, HOMC, CNT, AC, Gr. & $\begin{array}{l}\text { COMC with more structural ordering hexagonal pore system, larger surface area } \\
\text { and pore volume exhibits higher activity and selectivity }\end{array}$ & [90] \\
\hline Ethylbenzene & DUT-1, MCN-1, CMK-3 & $\begin{array}{l}\text { The novel mesoporous } \mathrm{C}_{3} \mathrm{~N}_{4} \text { (DUT-1) showed higher ethylbenzene conversion } \\
\text { than MCN-1 and CMK-3. }\end{array}$ & [89] \\
\hline Ethylbenzene & NMCS & $\begin{array}{l}\text { NMCS carbonized at } 800^{\circ} \mathrm{C} \text { demonstrated the best steady state catalytic perfor- } \\
\text { mance among all of the carbon nitride nanospheres }\end{array}$ & [115] \\
\hline Ethylbenzene & $\begin{array}{l}\text { G-M-CNT, A-M-CNT, MCSA-CNT, } \\
\text { MN-CNT, HN-CNT }\end{array}$ & $\begin{array}{l}\text { The defect- and surface } \mathrm{C}=0 \text { groups-rich } \mathrm{CN}_{x} \text { layer-free } \mathrm{N} \text {-doped CNTs (G-M-CNT) } \\
\text { prepared by different methods exhibit much superior } \\
\text { catalytic performance to their parent } \mathrm{CNT}\end{array}$ & $\begin{array}{l}{[83,84,88,} \\
128-130]\end{array}$ \\
\hline Ethylbenzene & ND/FLG & $\begin{array}{l}19 \mathrm{mmol} \mathrm{ST} \mathrm{g}^{-1} \mathrm{ND} \mathrm{h}^{-1} \mathrm{can}_{\text {be obtained over ND/FLG, and the synergistic effect }} \\
\text { exists in the hybrid }\end{array}$ & {$[47,86]$} \\
\hline Ethylbenzene & $\mathrm{N}-\mathrm{RGO} / \mathrm{ND}$ & $\begin{array}{l}\text { It shows much higher steady state styrene rate in comparison with the } \\
\text { mixture containing N-RGO and N-ND }\end{array}$ & [131] \\
\hline Ethylbenzene & $\mathrm{ND} / \mathrm{CN}_{x}$ & $\begin{array}{l}\mathrm{ND} / \mathrm{CN}_{x} \text { hybrid with appropriate } \mathrm{CN}_{x} \text { layer thickness shows significantly } \\
\text { improved catalytic performance in comparison with the parent ND }\end{array}$ & [87] \\
\hline Ethylbenzene & N-CNT-AC & $\begin{array}{l}\text { The N-doped nanotubes-decorated AC-based hybrid nanoarchitecture shows } \\
\text { much higher activity and selectivity }\end{array}$ & [85] \\
\hline Ethylbenzene & $\mathrm{N}-\mathrm{CNTs} / \mathrm{SiC}$ & $\begin{array}{l}\text { Hierarchical } \mathrm{N}-\mathrm{CNT} \text { on } \mathrm{SiC} \text { macroscopic host exhibits } 14 \% \text { of ethylbenzene con- } \\
\text { version with } 95 \% \text { of selectivity }\end{array}$ & [132] \\
\hline Ethylbenzene & $\mathrm{ND} / \mathrm{SiC}$ & $\mathrm{ND} / \mathrm{SiC}$ exhibits much superior styrene rate to ND & [133] \\
\hline Ethylbenzene & ND\&CNT/SiC & The monolith demonstrates higher activity, selectivity, and stability & {$[134]$} \\
\hline
\end{tabular}


was found that the catalytic performance of these mesoporous carbons was significantly dependent on their pore architecture. The initial activity ( $15 \mathrm{~min}$ on stream) at $600{ }^{\circ} \mathrm{C}$ measured by the conversion for OMC-1 and OMC-2 were $69.3 \%$ and $65.7 \%$ with propylene yields of $43.1 \%$ and $46.4 \%$, respectively, much better than that of the CMK-3 carbon catalyst (propane conversion of $54.3 \%$ with propylene yield of $15 \%$ ) were observed. It was worth noting that the propylene selectivity of $0 \mathrm{MC}-x$ remained almost unchanged over $100 \mathrm{~h}$, ascribed to the large void volume of the composite available for the gas stream, avoiding local transport limitation and hot spots. By replacing $\mathrm{HCl}$ with citric acid as the catalyst in the above synthesis process, a new mesoporous carbon (COMC) was prepared [90]. The COMC has more structural ordered hexagonal pore systems with a uniform pore size as well as the larger surface area, pore volume and pore size in comparison with HOMC (Fig. 15 (a)-(d)), which resulted from the more enhanced hydrogen interaction between the structural directing agent of triblock copolymer F127 and polymeric carbon precursor of resorcinol-formaldehyde resins. As a result, the COMC exhibited a much higher activity and selectivity for the DDH of propane than the HOMC and the other carbons, e.g., carbon nanotube CNT), activated carbon (AC) or graphite carbon (GC), as well as high stability (Fig. 15 (e)-(g)).

From the reaction mechanism for the DDH reaction, the introduction of nitrogen into the carbon matrix can improve the catalytic performance of carbocatalysts by increasing both the nucleophilicity of the $\mathrm{C}=0$ groups and the basic properties of the carbons. Therefore, we investigated the catalytic performance of mesoporous carbon nitride for the DDH reaction. Highly ordered mesoporous carbon nitride nanorods (DUT-1) with 971-1124 $\mathrm{m}^{2} \mathrm{~g}^{-1}$ surface area, $1.31-1.79 \mathrm{~cm}^{3} \mathrm{~g}^{-1}$ of pore volume, and $9.3-23 \mathrm{wt} \%$ of high $\mathrm{N}$ content were prepared by a

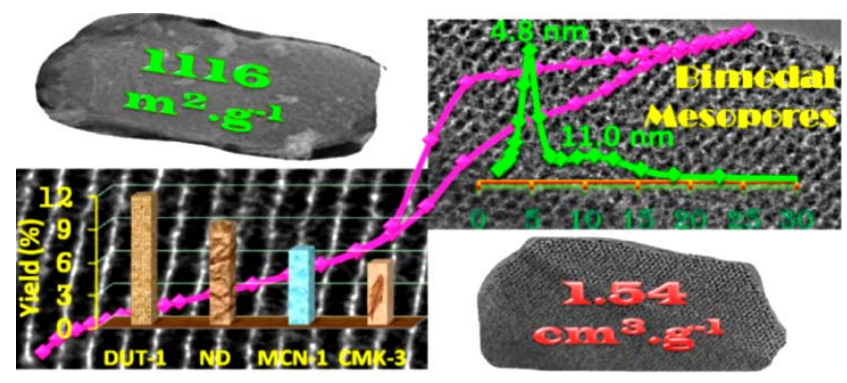

Fig. 16. Novel highly-ordered mesoporous carbon nitride and its catalytic performance in DDH of ethylbenzene to styrene under oxidantand steam-free conditions. Reproduced with permission from Ref. [89]. Copyright 2014, ACS.

facile nanocasting approach using SBA-15 as template and hexamethylenetetramine as carbon nitride precursor (Fig. 16) [89]. It was found that the specific surface area and pore volume as well as $\mathrm{N}$ content were strongly dependent on the precursor and pyrolysis temperature. This work breaks through the bottleneck problems for fabricating mesoporous carbon nitride with both high surface area (>1000 $\left.\mathrm{m}^{2} \mathrm{~g}^{-1}\right)$ and large pore volume $\left(>1 \mathrm{~cm}^{3} \mathrm{~g}^{-1}\right.$ ) by employing hexamethylenetetramine as the carbon nitride precursor. The current synthetic strategy can be extended to the preparation of various mesoporous carbon nitride with different textural characteristics by using different templates under different preparation conditions. The developed mesoporous carbon nitride material using $750{ }^{\circ} \mathrm{C}$ pyrolysis temperature exhibited a superior catalytic performance, ascribed to the promoting effect of nitrogen in the carbon matrix, the rich $\mathrm{C}=0$ group and defect/edge feature on the surface, small size of graphitic crystallite, as well as the high surface area and large pore volume. It can also be concluded that the tuneable microstructure via the preparation
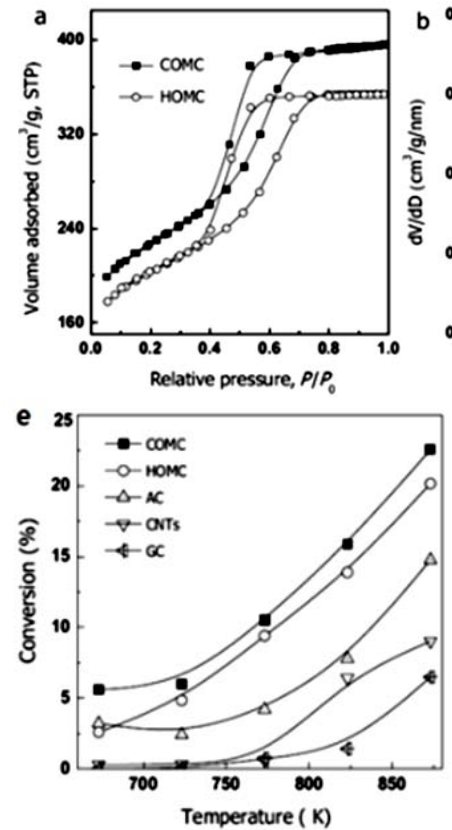
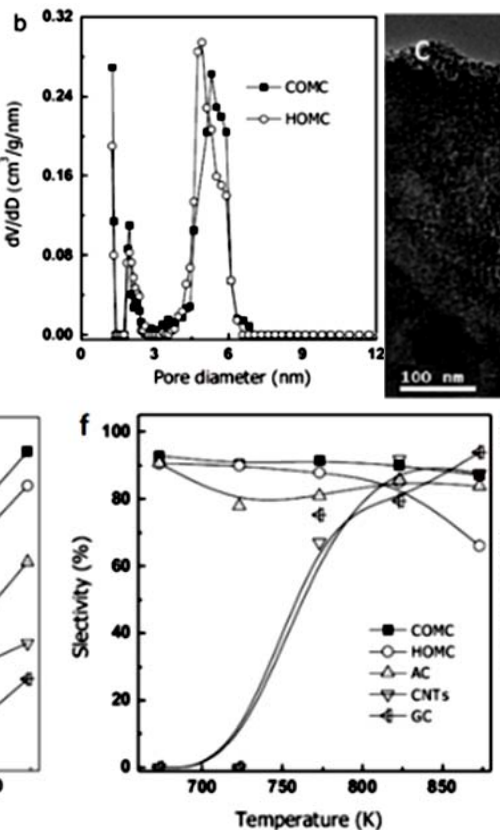
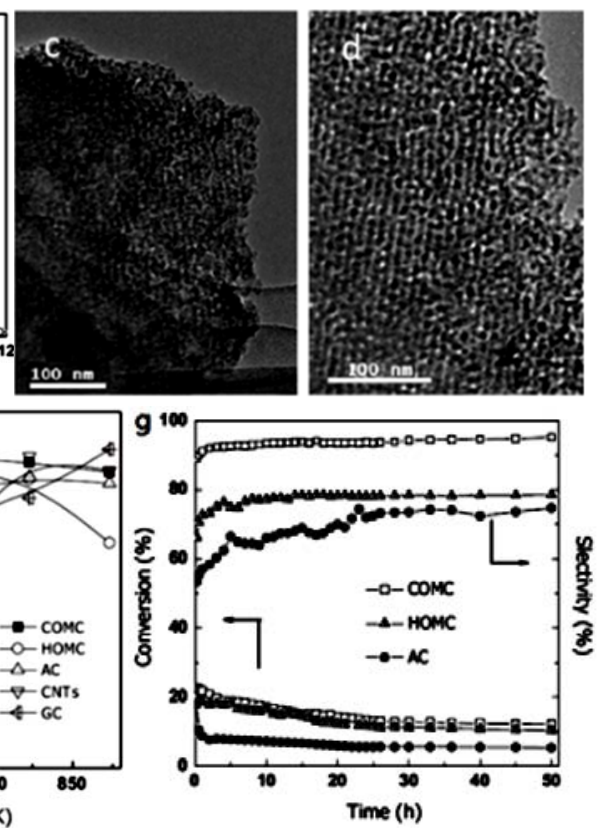

Fig. 15. Nitrogen sorption isotherms of COMC and HOMC (a), pore size distribution of COMC and HOMC (b), the TEM images of HOMC (c) and COMC (d), as well as the catalytic performance of HOMC, COMC, and the other included carbons for DDH of propane to propene (e-g). Reproduced with permission from Ref. [90]. Copyright 2012, Elsevier. 
process has a decisive influence on the catalytic performance.

The size of the mesoporous carbon nitride nanosphere can affect the diffusion of ethylbenzene, and therefore change the catalytic performance in the DDH of ethylbenzene. Su and coworkers [115] synthesized nitrogen-containing mesoporous carbon nanospheres (NMCS) with a comparatively uniform and tunable size by an aqueous self-assembly process with F127 as template and morphological control agent, and 3-aminophenol as carbon and nitrogen sources. The sphere sizes can be simply tuned by optimizing the concentration of F127 and ammonia. Fig. 17 presents the SEM images of NMCS-1-600 (without F127, $600{ }^{\circ} \mathrm{C}$ carbonization), NMCS-4-600 (with F127, $600{ }^{\circ} \mathrm{C}$ carbonization), and NMCS-4-800 (with F127, $800{ }^{\circ} \mathrm{C}$ carbonization) as well as their catalytic performance in the DDH of ethylbenzene to styrene under oxidant- and steam-free conditions. They found that F127 performed not only as a soft template for forming the mesostructure, but also as a morphological control agent in this aqueous process. In comparison to NMCS-1-600, NMCS-4-600 exhibited a better styrene rate $(1.2$ mmol g-1 $\mathrm{h}^{-1}$ vs. $0.8 \mathrm{mmol} \mathrm{g}^{-1} \mathrm{~h}^{-1}$ ) and they have similar styrene selectivity (95\%) at $14 \mathrm{~h}$, ascribed to the easy accessibility of the catalytic active sites ( $\mathrm{C}=0$ and quinone) in NMCS-4-600 for ethylbenzene molecules because the two materials have similar specific surface areas, $\mathrm{O}$ content, and $\mathrm{N}$ content, except that NMCS-4-600 has an open mesostructure. As the carbonization temperature rises from 600 to $800{ }^{\circ} \mathrm{C}$, the sphere size decreases from 225 to $163 \mathrm{~nm}$. According to the $\mathrm{N}_{2}$ adsorption results, the specific surface areas were $497 \mathrm{~m}^{2} \mathrm{~g}^{-1}$ for NMCS-4-600 and $793 \mathrm{~m}^{2} \mathrm{~g}^{-1}$ for NMCS-4-800. The total pore volumes were 0.36 $\mathrm{cm}^{3} \mathrm{~g}^{-1}$ for NMCS-4-600 and $0.54 \mathrm{~cm}^{3} \mathrm{~g}^{-1}$ for NMCS-4-800. As a result, the NMCS-4-800 exhibited the best steady state catalytic performance.

Recently, N-doped carbonaceous materials including
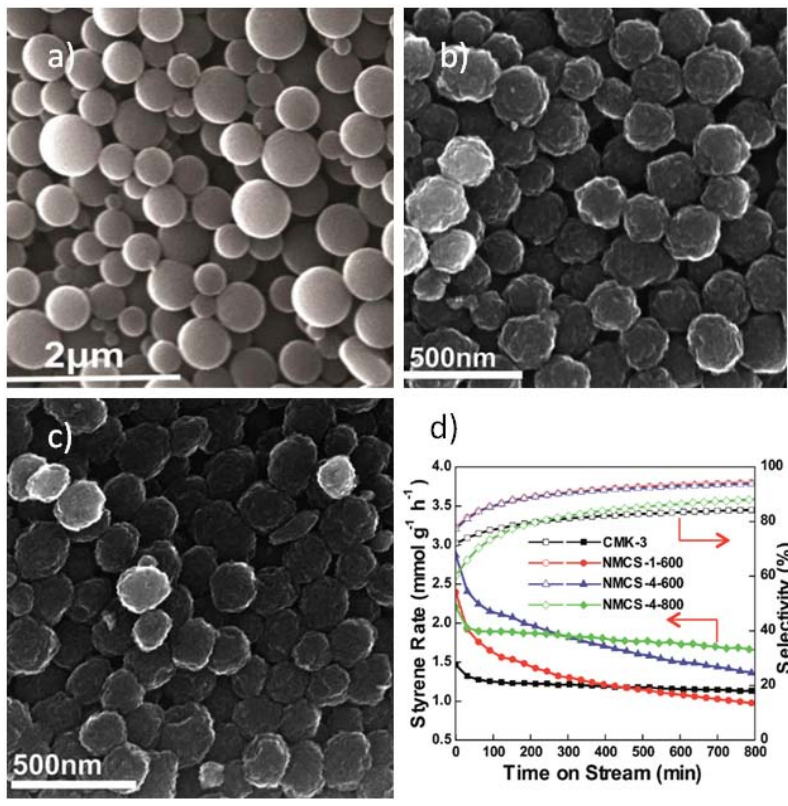

d)

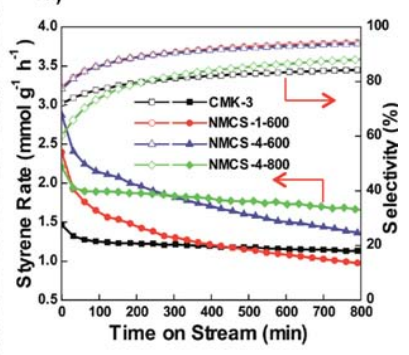

Fig. 17. SEM images of NMCS-1-600 (a), NMCS-4-600 (b), and NMCS-4-800 (c) as well as their catalytic performance in DDH of ethylbenzene to styrene under oxidant- and steam-free conditions. Reproduced with permission from Ref. [115]. Copyright 2015, RSC.
$\mathrm{N}$-doped graphene, carbon nanotube, fullerene, carbon nanosphere, diamond, nanofiber, nanosheet, carbon dot, porous carbon, and their composites have been extensively applied in heterogeneous catalysis (thermocatalysis, photocatalysis and electrocatalysis) [37,116-122]. The N-doped carbon materials can be synthesize by two different methods: direct synthesis and post treatment. The former has the potential to fabricate homogeneous doping materials, but the fabrication of $\mathrm{N}$-doped carbon nanostructures with different morphologies by direct synthesis still remains a challenge. However, the post treatment can be considered a facile strategy for synthesizing many $\mathrm{N}$-doped nanostructured carbonaceous materials. $\mathrm{NH}_{3}$ can be used for N-doping through post treatment. However, owing the high toxicity and strong corrosiveness of $\mathrm{NH}_{3}$ inhibit it from use as a promising $\mathrm{N}$ precursor. Therefore, the pyrolysis of carbon materials with different $\mathrm{N}$-containing precursors like melamine, pyridine, urea, etc. is an extensively adopted method [123-127]. The pyrolysis method using N-containing organic molecules has an inherent disadvantage: high temperature resulting in low doping level due to breaking the $\mathrm{C}-\mathrm{N}$ bond at high temperature, but a low pyrolysis temperature would lead to a thicker $\mathrm{CN}_{x}$ layer coating on the carbon nanostructure, which deteriorates their catalysis by covering the surface active sites $[87,125]$. In order to achieve highly active carbocatalysts, it is highly desirable to create surface $\mathrm{CN}_{x}$ layer-free $\mathrm{N}$-doped carbonaceous nanostructures with higher $\mathrm{N}$-doping at a lower pyrolysis temperature. We previously reported that the introduction guanidine nitrate into the pyrolysis process of carbon nanotubes with melamine can efficiently remove the $\mathrm{CN}_{x}$ layers (Fig. 18) [88], which can improve the accessibility of surface $\mathrm{C}=\mathrm{O}$ active sites for the $\mathrm{DDH}$ reaction of ethylbenzene to styrene. As the same time, the introduction of guanidine nitrate also adjusted the surface structure and surface chemistry. As a result, the synthesized $\mathrm{CN}_{x}$ layer free N-doped CNT (G-M-CNT) by the guanidine nitrate assisted pyrolysis of melamine approach exhibited outstanding catalytic performance in the DDH of ethylbenzene. The introduction of guanidine nitrate into the pyrolysis process to remove the $\mathrm{CN}_{x}$ layers on the carbon nanotubes has been previously established [88]. However, by adopting the above method, excessive chemical reagents were used, and this is not a clean and economical approach. Therefore, it is highly desirable to develop a facile, low cost and clean approach for fabricating a $\mathrm{CN}_{X}$ layer-free nitrogen-doped CNT catalyst. In our further studies, we presented a facile, clean and efficient prior air activation method [128], in which the air activation treatment was inserted in the process of $\mathrm{N}$-doping of CNT (A-M-CNT). By this approach, a $\mathrm{CN}_{x}$ layer free $\mathrm{N}$-doped CNT was successfully prepared, which showed a superior catalytic performance in the DDH of ethylbenzene to the classical $\mathrm{N}$-doped CNT in the absence of the prior air activation process and the parent CNT.

Furthermore, a facile and scalable approach to efficiently tune the microstructure and surface chemical properties of $\mathrm{N}$-doped carbocatalysts through a controlled glucose hydrothermal treatment with different parameters and subsequent pyrolysis of pretreated carbonaceous materials with melamine (GHT-PCM) was presented [84]. Characterization techniques 

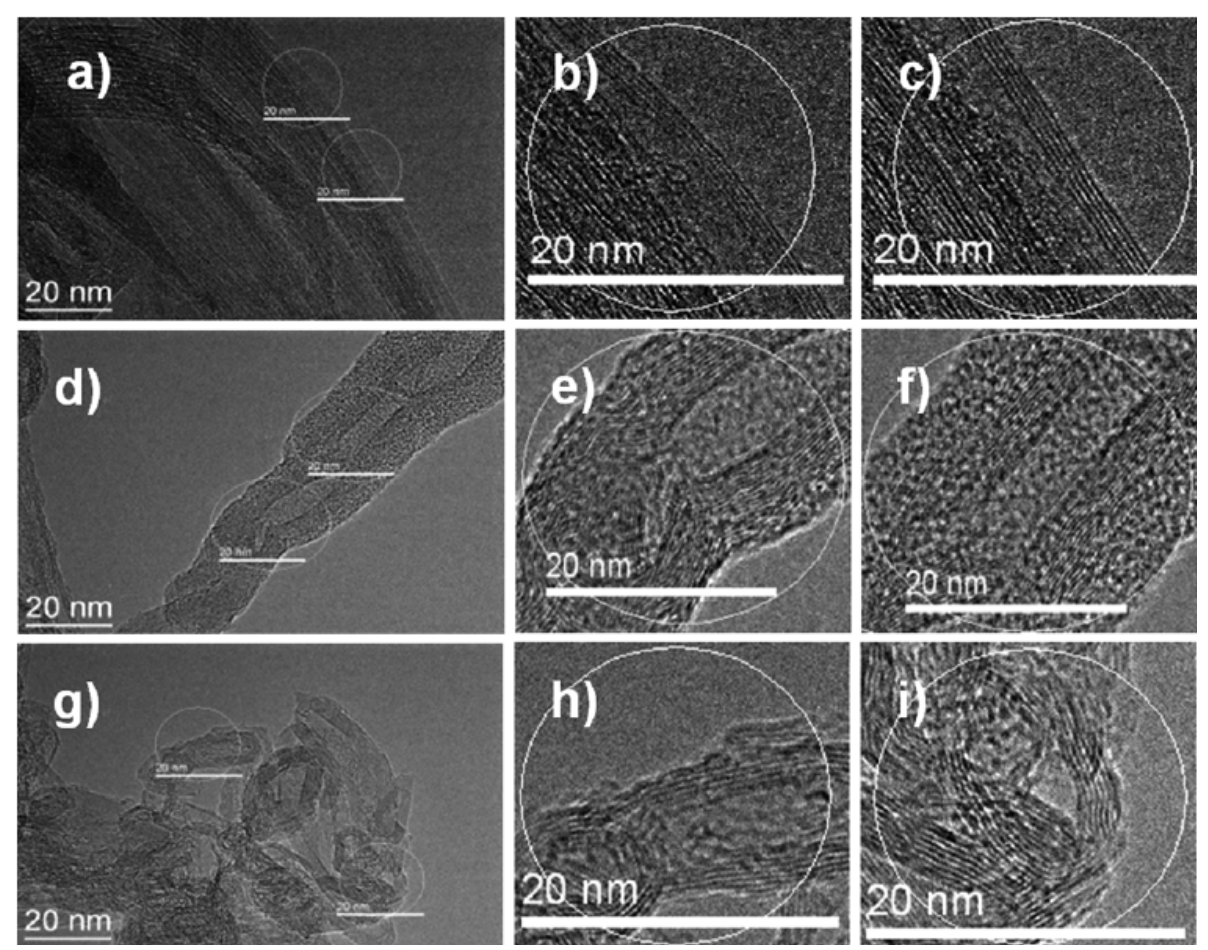

Fig. 18. Typical HRTEM images of (a) pristine CNT with (b, c) the magnified regions marked in (a); (d) M-CNT with (e, f) the magnified regions marked in (d); and (g) G-M-CNT with (h, i) the magnified regions marked in (g). Reproduced with permission from Ref. [88]. Copyright 2015, Wiley-VCH.

identified the effect of prior GHT on the microstructure and surface chemical properties of $\mathrm{N}$-doped carbocatalysts, as well as revealed the relationship between catalyst nature and catalytic performance in the DDH of ethylbenzene for styrene production. It was found that the GHT process and its conditions significantly affected the microstructure and surface chemical properties of the $\mathrm{N}$-doped carbocatalysts, which subsequently influenced their catalytic performance in the DDH reaction dramatically. Interestingly, the prior GHT can remove the carbon nitride layer formed on the parent nanocarbon in the process of melamine pyrolysis, produce structural defects, and tune the surface element component through the "detonation" of the polysaccharide coating on the nanocarbon. The N-doped CNT (M-Glu-CNT) prepared by the established GHT-PCM approach demonstrated a higher catalytic performance $(4.6 \mathrm{mmol}$ $\mathrm{g}^{-1} \mathrm{~h}^{-1}$ styrene rate with $98 \%$ selectivity) to the common $\mathrm{N}$-doped CNT (M-CNT, $3.4 \mathrm{mmol} \mathrm{g}^{-1} \mathrm{~h}^{-1}$ styrene rate with $98.2 \%$ selectivity) as well as to pristine CNT (2.8 $\left.\mathrm{mmol} \mathrm{g}^{-1} \mathrm{~h}^{-1}\right)$ styrene rate with $96.8 \%$ selectivity). This was ascribed to increased structural defects, enriched surface ketonic $\mathrm{C}=\mathrm{O}$ groups, and improved basic properties from $\mathrm{N}$-doping on the M-Glu-CNT, which strongly depended on GHT conditions. The excellent catalytic performance of the developed M-Glu-CNT catalyst endows it with great potential for future clean production of styrene via oxidant- and steam-free conditions. Moreover, the directed GHT-PCM strategy can be extended to other $\mathrm{N}$-doped carbonaceous materials like mesoporous carbon for enhanced catalytic performance in the DDH reaction by tuning their microstructure and surface chemistry.

Recently, our research group developed a robust method for simultaneous $\mathrm{N}$-doping, defect forming and the removal of formed $\mathrm{CN}_{x}$ layer in the $\mathrm{N}$-doping process by the explosive decomposition of a melamine cyanuric acid supramolecular assembly. The synthesized N-doped CNT was denoted as MCSA-CNT [83]. The explosive decomposition approach was further developed by employing melamine nitrate and hexamethylenetetramine nitrate $[129,130]$. The further strengthened effect on defect forming was realized, besides the $\mathrm{N}$-doping and formed $\mathrm{CN}_{x}$ layers elimination. Novel N-doped CNTs with increased active sites and their accessibility have been developed, which exhibited excellent catalytic properties for the DDH of ethylbenzene. The facile and efficient one-step approach for simultaneously producing defects, enriching with surface $\mathrm{C}=\mathrm{O}$ groups, and $\mathrm{N}$-doping also paved a new way for the preparation of other $\mathrm{N}$-doped nanocarbon catalysts with outstanding catalytic performance in different transformations.

Nanodiamond (ND) and carbon nanotube (CNT) have been established as candidates for dehydrogenation reactions of hydrocarbons to olefins including ODH and DDH. The microstructure of ND and CNT can be adjusted by a bottom up approach in the synthesis process or post-treatment. The fabrication of ND- and CNT-based hybrids is another efficient strategy for tuning their microstructure, and which in turn adjusts their catalytic performance. Pham-Huu and coworkers $[86,47]$ successfully prepared a ND/FLG hybrid by mixing a suspension of FLG (few-layer graphene) in ethanol with ND (nanodiamond). In this hybrid, FLG plays the role of a 2D support for dispersing ND clusters while ND acting as a nano-spacer for partly preventing the re-stacking of the FLG sheets (Fig. 19(a)-(c)). Then they compared the catalytic performance of ND, FLG, and the 

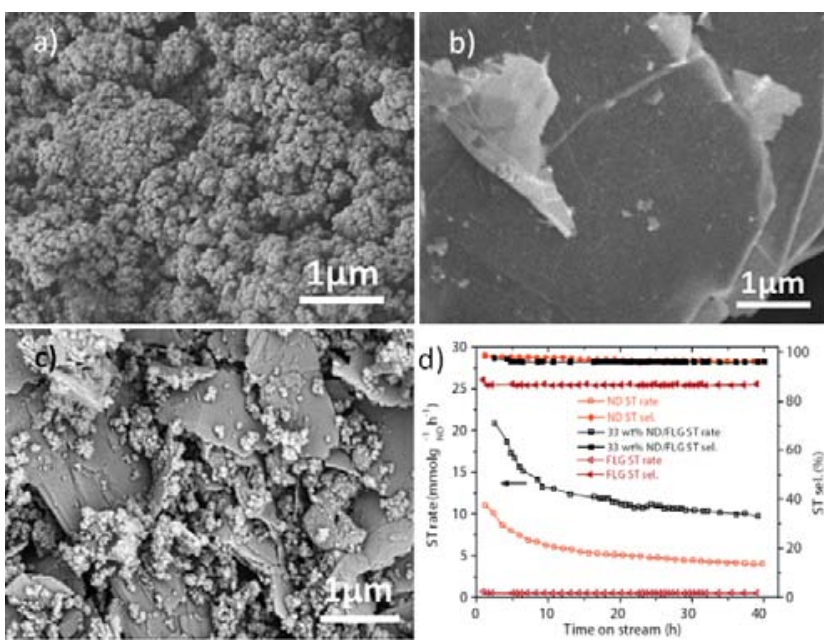

Fig. 19. SEM images of nanodiamond (a), few-layer graphene, and the hydrid composed of nanodiamond and few-layer graphene (c), as well as the catalytic performance (d) in DDH of ethylbenzene over the diverse carbocatalysts including nanodiamond (ND), few-layer graphene (FLG) and the hybrid (33 wt\% ND/FLG). Reproduced with permission from Ref. [45]. Copyright 2015, Elsevier.

synthesized ND/FLG hybrid for the DDH of ethylbenzene to styrene (Fig. 19(d)). It was found that the hybrid materials displayed not only the individual properties of ND and graphene, but also those resulting from a synergism when they closely interact. The ND/FLG hybrid catalyst exhibited the highest DH activity among the tested catalysts, especially with a dehydrogenation specific rate as high as $19 \mathrm{mmol} \mathrm{ST} \mathrm{g}^{-1} \mathrm{ND} \mathrm{h}^{-1}$ along with a selectivity to styrene up to $95 \%$ at $600{ }^{\circ} \mathrm{C}$.

Owing to unique structural and surface properties, both graphene and nanodiamond have attracted tremendous attention in catalysis, separation, biosensor, drug-delivery, optical and optoelectronic devices, energy conversion and storage. However, the re-stacking of exfoliated graphene nanosheets and dispersed nanodiamond inevitably decreased their application properties. In our previous report, we first successfully realized the simultaneous re-stacking inhibition by fabricating $\mathrm{N}$-doped mesoporous graphene/nanodiamond nanocomposite (N-RGO/ND) through a facile wet-chemical assembly strategy, using hexamethylenetetramine (HTM) as dispersant and nitrogen precursor (Fig. 20 (A), (B)) [131]. The DDH of ethylbenzene was performed to demonstrate the benefits of this carbon nanoarchitecture in catalysis. The results clearly showed that the catalytic performance was strongly dependent on the microstructure of carbon materials. $4.11 \mathrm{mmol} \mathrm{g}^{-1} \mathrm{cat} \mathrm{h}^{-1}$ of steady-state yield of styrene with $97 \%$ of selectivity was achieved, demonstrating 1.58, and 1.52 times the steady state styrene rate of pristine graphene and nanodiamond, respectively, and it demonstrated 6.13 times the steady state styrene rate of the industrial K-Fe catalyst (Fig. 20(C)). This was ascribed to a synergistic effect between graphene and nanodiamond in the mesoporous nanoarchitecture, as well as the promoting effect of nitrogen doping. The superior catalytic performance of N-RGO/ND allows it to be a potential catalyst for the future industrial application of styrene production.

Through a facile pyrolysis of pristine nanodiamond and melamine at temperatures of 650,700 , and $750{ }^{\circ} \mathrm{C}$, based on the parent nanodiamond (ND, Fig. 21(a), we prepared nanodiamond/carbon nitride $\left(\mathrm{ND} / \mathrm{CN}_{x}\right)$ nanoarchitectures with a stacked carbon nitride layer on ND (Fig. 21 (b)-(d)) [87], which challenged the long-held axiom that a $\mathrm{CN}_{x}$ layer can only be formed at condensation temperatures of less than $600{ }^{\circ} \mathrm{C}$ and it decomposes and inserts into the carbon matrix at temperatures higher than $600{ }^{\circ} \mathrm{C}$. When the pyrolysis temperature was further increased to $800{ }^{\circ} \mathrm{C}$, the formed $\mathrm{CN}_{x}$ layers disappeared (Fig. 21(e)). The microstructure of the ND-containing hybrids were strongly dependent on the pyrolysis temperature. From Fig. 21(f), ND/CN ${ }_{x}-750$ exhibited the best catalytic performance in the DDH of ethylbenzene for styrene production, which resulted from the promoting effect of a $\mathrm{CN}_{X}$ layer with an appropriate amount on ND, as well as to the $\mathrm{C}=0$ group- and defect-rich surface features.

Moreover, in our ACM research group, a novel N-doped ac-
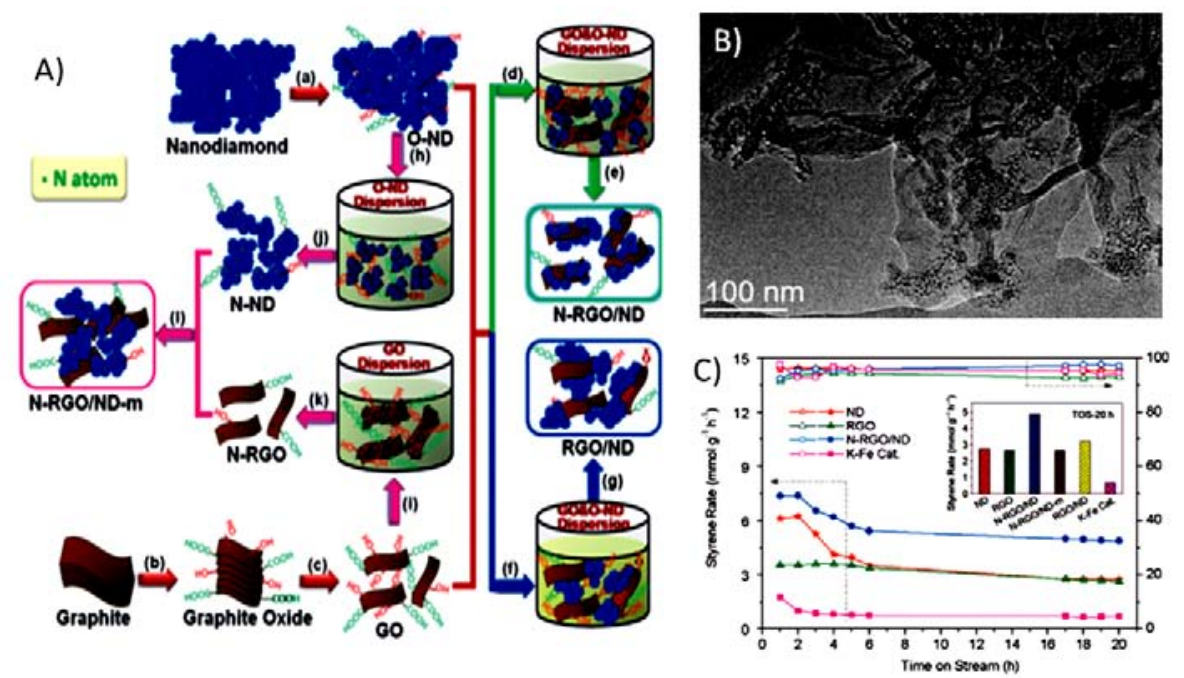

Fig. 20. The schematic illustration of the preparation process (A), the TEM image (B), and the catalytic performance in DDH of ethylbenzene (C) of the as-synthesized mesoporous N-RGO/ND hybrid. The diverse carbocatalysts like ND, RGO, N-RGO/ND-m (mixture of N-RGO and N-ND), RGO/ND (absence of hexamethylenetetramine) and K-Fe were included for comparison. Reproduced with permission from Ref. [131]. Copyright 2015, Wiley-VCH. 

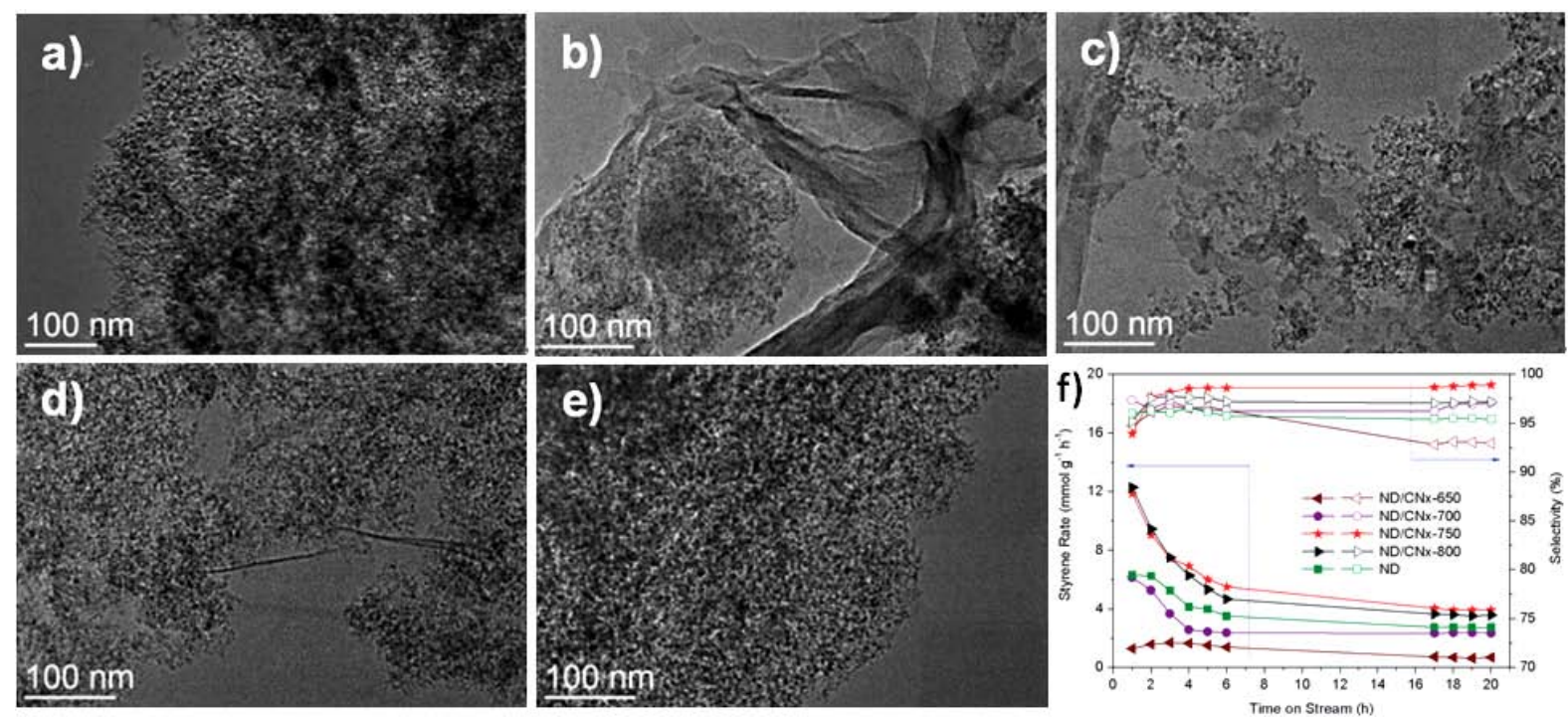

Fig. 21. TEM images of the nanodiamond (a) and the nanodiamond/carbon nitride hybrids including $N D / \mathrm{CN}_{x}-650$ (b), ND/CN $x_{x}-700$ (c), ND/CN $x-750$ (d), and $\mathrm{ND} / \mathrm{CN}_{x}-800$ (e) prepared with diverse pyrolysis temperatures of $650,700,750$, and $800{ }^{\circ} \mathrm{C}$, and their catalytic performance in DDH of ethylbenzene to styrene (f). Reproduced with permission from Ref. [87]. Copyright 2014, RSC.

tivated carbon (AC) based nanostructure decorated with nanotubes (N-CNT-AC) was successfully fabricated by a facile and scalable approach involving mechanical milling and subsequent solid pyrolysis of the low cost and commercially available AC and melamine (Fig. 22 (a)-(c)) [85]. It was found that although the as-synthesized N-CNT-AC hybrid had a much lower surface area $\left(397.0 \mathrm{~cm}^{2} / \mathrm{g}\right)$ and pore volume $(0.17$ $\left.\mathrm{cm}^{3} / \mathrm{g}\right)$ than the parent AC $\left(777.1 \mathrm{~cm}^{2} / \mathrm{g}\right.$ surface area and 0.4 $\mathrm{cm}^{3} / \mathrm{g}$ pore volume), it demonstrated 1.74 times the steady state styrene rate of the per gram parent AC for the DDH reaction (Fig. 22(d)). This was ascribed to the promoting effect of the unique hybrid microstructure, rich surface $\mathrm{C}=0$ groups and defect/edge features, increased basic properties through $\mathrm{N}$-introduction into the hybrid nanostructure, small size of the graphitic crystallite, as well as the inherent high surface area and large porosity of the AC-based materials, which were con-
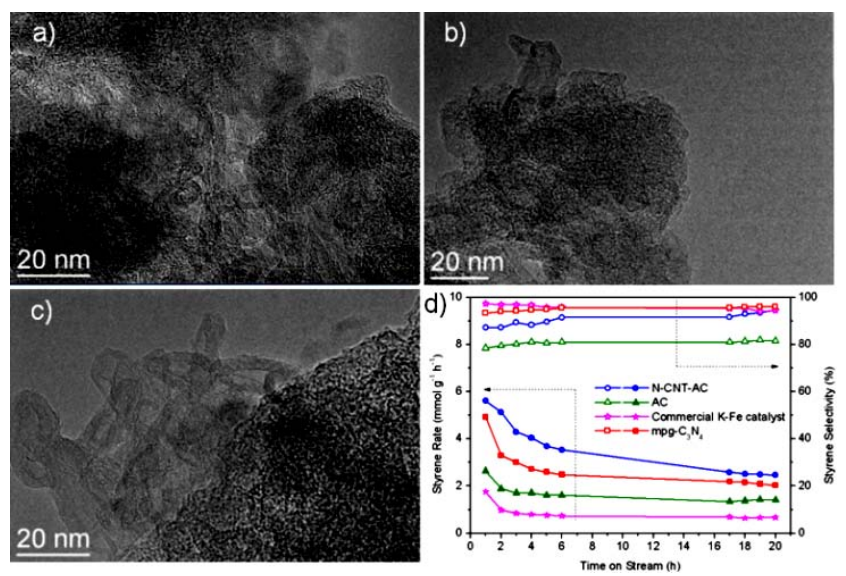

Fig. 22. HRTEM images at different regions $(\mathrm{a}-\mathrm{c})$ of the as-prepared $\mathrm{N}$-doped AC-based hybrid nanostructure (N-CNT-AC), and the catalytic performance of the as-synthesized N-CNT-AC as well as AC, K-Fe, and mpg- $\mathrm{C}_{3} \mathrm{~N}_{4}$ catalysts for DDH reaction of ethylbenzene (d). Reproduced with permission from Ref. [85]. Copyright 2015, RSC. firmed by TEM, BET, XRD, Raman, XPS. The in situ Fourier transform infrared spectroscopy measurement suggested a lower activation energy on the developed N-CNT-AC nanostructure for the DDH reaction than over the parent AC.

As is demonstrated above in Section 3.1.1, the powder form of the material renders it difficult to use in large scale applications, especially in heterogeneous catalysis due to high pressure drop across the catalyst bed and difficulty in handling powder. Pham-Hunn's group [132,133] and Yang's group [134] developed an efficient approach to address these issues. Pham-Hun's group reported a method for preparing hierarchical N-CNT on a SiC macroscopic host (N-CNTs/SiC) catalyst [132]. The catalytic performance in the DDH of ethylbenzene was measured at $550{ }^{\circ} \mathrm{C}$. From Fig. 23(a), the N-CNTs/SiC macroscopic structure exhibited a similar conversion to that on N-CNTs, although with only $40 \%$ mass loading on the SiC host. $14 \%$ ethylbenzene conversion with $95 \%$ styrene selectivity were obtained on the N-CNTs/SiC catalyst, but only $8.1 \%$ of conversion with $88.2 \%$ selectivity were on $\mathrm{SiC}$ after $10 \mathrm{~h}$ of time on stream (Fig. 23(a)). Interestingly, from Fig. 23(b), the $\mathrm{N}$-CNTs/SiC demonstrated 2.3 times higher styrene rate (mol $\mathrm{g}^{-1} \mathrm{~N}-\mathrm{CNT} \mathrm{h}^{-1}$ ) than N-CNTs, which was ascribed to the improved accessibility of active sites to reactants [132]. In addition, based on the established ND catalyst for the DDH reaction, they fabricated a new hybrid structure consisting of a ND-decorated porous $\beta$-SiC foam matrix (13 wt $\% \mathrm{ND} / \beta-\mathrm{SiC}$ ), which was investigated as a metal-free catalyst in the DDH of ethylbenzene to styrene (Fig. 24) [133]. The hybrid foam catalyst displayed excellent styrene rate and stability in the DDH of ethylbenzene to styrene. It exhibited 3.8 times higher styrene rate than the powder-form NDs without losing styrene selectivity (98\%). Thus this demonstrated the high catalytic efficiency for the styrene production via the DDH reaction. The much superior styrene rate $\left(12.9 \mathrm{mmol} \mathrm{g}^{-1} \mathrm{ND} \mathrm{h}^{-1}\right)$ over the 13 $w \mathrm{t} \% \mathrm{ND} / \beta$-SiC to ND can be ascribed to the higher dispersion 

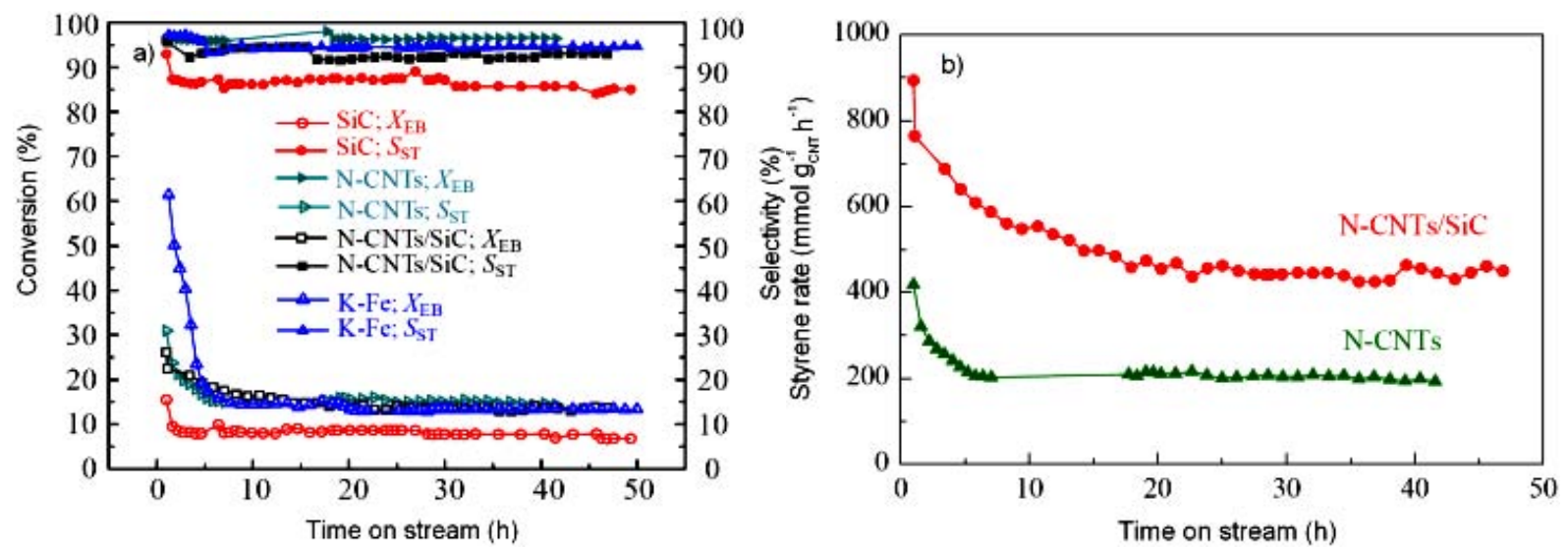

Fig. 23. Catalytic performance including conversion and selectivity (a) as well as styrene rate (b) in DDH of ethylbenzene over N-CNTS/SiC, N-CNT, pristine $\mathrm{SiC}$, and commercial K-Fe catalysts [132].
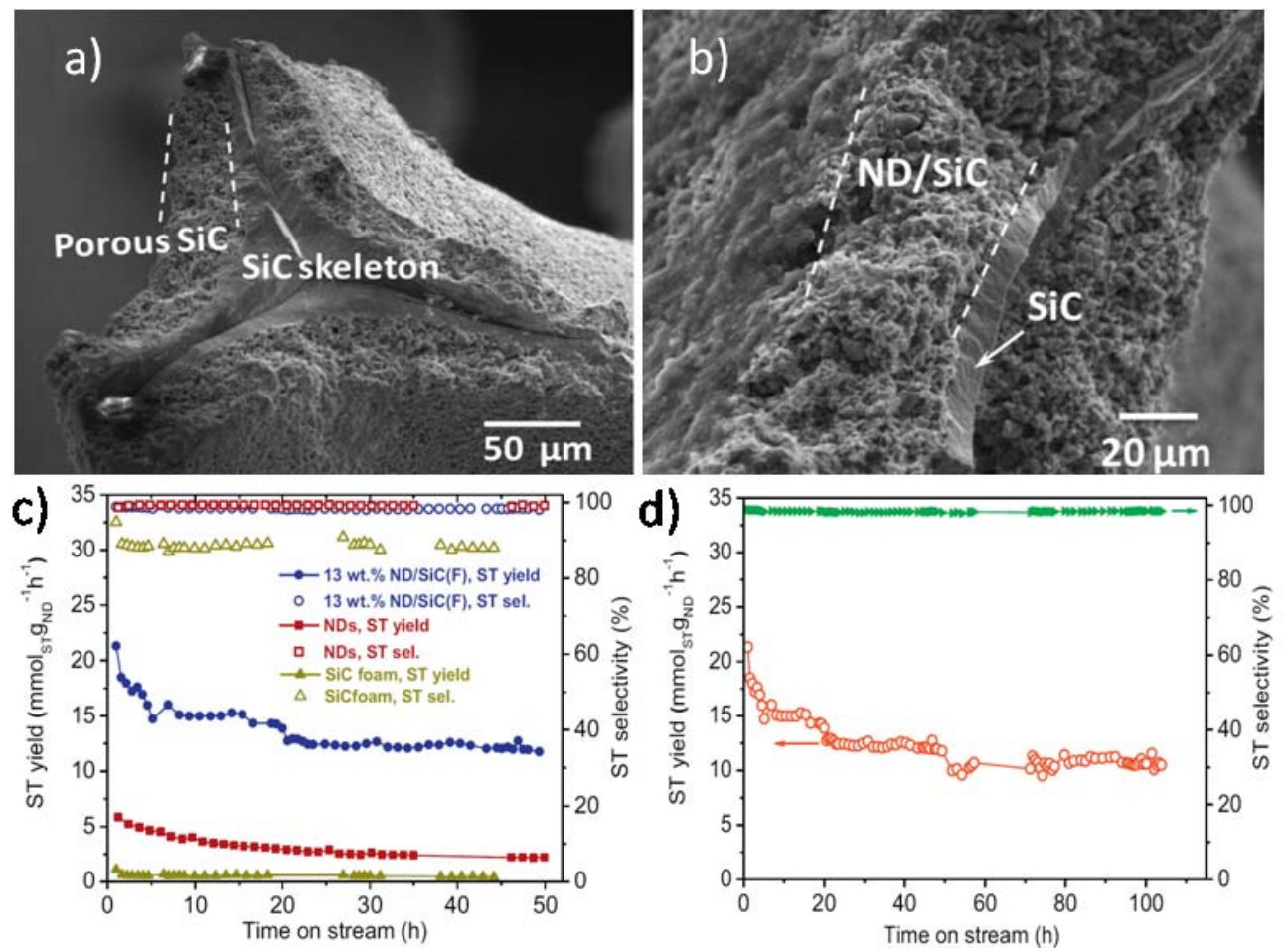

Fig. 24. SEM images of $\beta$-SiC foam (a) and the as-synthesized macroscopic ND/ $\beta$-SiC foam catalyst (b) as well as styrene rate over ND, $\beta$-SiC foam, and $13 \mathrm{wt} \% \mathrm{ND} / \beta$-SiC foam catalyst and the long-term stability of $13 \mathrm{wt} \% \mathrm{ND} / \beta$-SiC foam catalyst for DDH reaction of ethylbenzene [133]. Reproduced with permission from Ref. [133]. Copyright 2015, Elsevier.

of ND on the SiC surface, which provided a higher density of active sites for the reaction and also to the possible microturbulence generated through the contact between the reactant and the SiC foam structures. From Fig. 24(d), the excellent catalytic stability and styrene rate over the ND/SiC foam catalyst still remained at $10.97 \mathrm{mmol} \mathrm{g}^{-1} \mathrm{~h}^{-1}$ with $98 \%$ of styrene selectivity after $100 \mathrm{~h}$ of reaction, which renders it a promising catalyst for industrial applications. The high resistance towards deactivation of ND/SiC can be attributed to the open porosity of the support and a connected pore which significantly reduced the residence time of the products on the active sites and as a consequence, the amount of carbonaceous deposit.

$\mathrm{Su}$ and coworkers [134] reported a facile two-step synthesis method to produce a ND\&CNT/SiC monolith (Fig. 25(A)), which contains a macroporous $\mathrm{SiC}$ foam as the support and in situ grown carbon nanotubes (CNTs) on the SiC support as the coating layer. The commercially available ND aggregates as the active sites were supported onto the CNT coating layers by a sonication-assisted impregnation method. The ND\&CNT/SiC monolith features a CNT layer that was completely coated on the macroporous $\mathrm{SiC}$ foam and commercial ND aggregates were uniformly embedded into the 3D CNT networks (Fig. 25 (B), (C)). The catalytic performance of ND, CNT/SiC, and ND\&CNT/SiC in DDH of etlylbenzene to styrene was tested (Fig. 25 (D), (E)). The ND\&CNT/SiC monolith gave 19.4\% ethylbenzene conversion with $98.3 \%$ selectivity to styrene after $14 \mathrm{~h}$, which were higher than those of the pure CNT/SiC catalyst (3.8\% conversion with $88.7 \%$ selectivity) and even commercial 

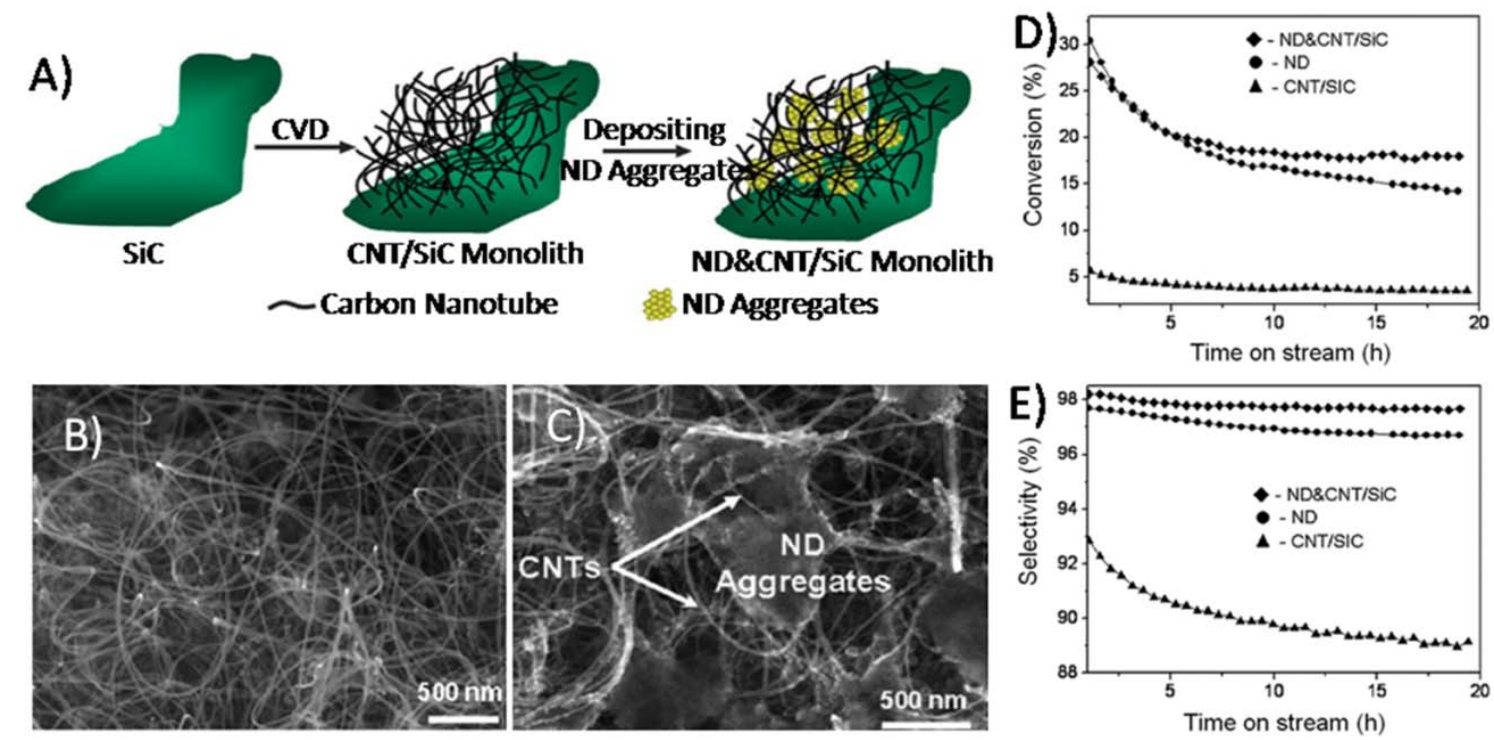

Fig. 25. Schematic illustration for preparing ND/CNT-SiC monolith (A), and the SEM images of CNT/SiC monolith (B) and ND\&CNT/SiC monolith (C), as well as the conversion of ethylbenzene (D) and selectivity of styrene (E) for DDH of ethylbenzene to styrene. Reproduced with permission from Ref. [134]. Copyright 2014, RSC.

ND powders (15.1\% conversion with $97.1 \%$ selectivity). The conversion of ethylbenzene over the ND/CNT-SiC monolith quickly stabilized after just $7 \mathrm{~h}$, but the commercial ND powder cannot be kept stable even after $20 \mathrm{~h}$. The possible reasons for the better performance of the ND\&CNT/SiC monolith can be ascribed to its high effective surface area and short diffusion length of this hierarchical CNT/SiC support which favored the diffusion/desorption of the reactants and products, and also the heat transfer over the $\mathrm{SiC}$ support during the reaction. However, for the commercial ND powder, the mass and heat transfer were not so fast.

In summary, the morphology, shape, size, and texture of carbon materials can be efficiently adjusted by the bottom up approach in the synthesis or post-treatment, which in turn efficiently tunes the catalytic performance including activity, selectivity and stability of carbocatalysts for the ODH and DDH reaction of hydrocarbons. This can be ascribed to the faster diffusion and desorption of the reactants and products, and also heat transfer. Different types of carbon materials have different surface structure and surface chemistry, which has been summarized for the effect on morphology, shape, size, and texture. Therefore, for the adjustment of surface structure and surface chemistry as follows, this review will emphasize the post treatment approach, and not on the types of carbon materials.

\subsection{Surface structure}

Generally, perfect graphitic planes are inactive, but the structural defects, edge planes, and vacancies on graphitic carbons are active due to the localization of $\pi$-electron at these places and the resulting deviation of the $\mathrm{C}$ hybridization states from $\mathrm{sp}^{2}$ to $\mathrm{sp}^{x}$ by $\pi$-electron localization. In fact, there are no perfect planes without any defects, edge planes, or vacancies. It was established that the structural defects, edge planes, and vacancies and the formed ketonic carbonyl groups on these active carbon places are catalytic active sites for the dehydrogenation of hydrocarbons $[4,5,135,136]$. However, the structural defects, edge planes, and vacancies can lead to the over-oxidation for ODH reaction when oxygen is used as oxidant $[63,137,138]$. However, these defects do not lead to over-oxidation when mild oxidants like $\mathrm{CO}_{2}$ is used. For the DDH process, no over-oxidation exists, and therefore more defects can give better catalytic performance. However, we cannot say that more defects always give a better carbocatalyst. Many other properties like mechanical stability must be taken into account. We can safely say that the controllable formation of surface defects on the carbon materials is desirable. Structural defects, edge planes, and vacancies can be produced by post treatment like oxidation treatment, ball milling, etc. HRTEM and Raman spectroscopy are powerful tools to characterize the surface structures like structural defects, edge planes, and vacancies. In this section, the modulation of structural defects, edge planes, and vacancies for both the ODH and DDH reactions of hydrocarbons is reviewed. Of course, the tuning of defects, edge planes, and vacancies can either increase and decrease the performance for the $\mathrm{ODH}$ reaction since too many defects, edge planes, and vacancies can result in low selectivity by over-oxidation and poor stability by carbon combustion.

\subsubsection{ODH reaction}

Carbon nanofibers (CNFs) have been established as promising carbocatalysts for the ODH reaction, but the further improvement in catalytic performance is required. Zhao, et al. [68] synthesized carbon nanofibers with systematically varied graphitic platelet orientations, changing the CNF properties such as the amount of basic groups, the crystallinity, and the ratio between the prismatic area and the basal plane area. It was found that the formation of oxygen-containing groups was relatively difficult on the basal sites due to the highly integrated 
carbon atoms in the graphitic platelets below $400{ }^{\circ} \mathrm{C}$. However, oxygen species can easily be formed with the carbon atoms at the edge sites. As a result, the CNT20 with more edge planes showed much better catalytic performance in the ODH of ethylbenzene than the others. Furthermore, Su and coworkers [70] clearly proved that surface defects produced by activation under ODH reaction conditions were responsible for the increased catalytic activity of the carbonaceous catalysts in the ODH of ethylbenzene.

For the tuning of the surface structure, a facile and efficient method is highly desirable. It was found that ball milling can produce many sectional defects located on exposed edges or terminals of MWCNTs and these defects can induce the formation of more hydroxyl groups by an alkali-assisted hydroxylation, which significantly improved the catalytic performance of the MWCNTs in the ODH of ethylbenzene in the presence of $\mathrm{CO}_{2}$ [65]. Generally, graphitic carbon contains two planes: the edge plane and the basal plane. The edge plane is usually more reactive than the basal plane. The graphitic structure in glassy carbon are curved and form continuous fullerene-like structures with loops. Therefore, the basal plane dominates the surface of glassy carbon.

Although the structural defects, edges, and vacancies are active for the ODH reactions, too many of these can lead to over-oxidation in the presence oxygen. As a result, the selectivity of carbocatalysts can be suppressed $[63,82,137,138]$. Boric or phosphorus oxide as an electron-deficient promoter tends to inhibit the dissociative adsorption of oxygen and sustains the selective oxygen species on the catalyst surface. Su and coworkers synthesized borate and phosphate modified carbon nanotubes (CNTs) with different loadings and measured their catalytic performance for the ODH of isopentane. They found that a decrease in isopentane conversion and increase in alkene selectivity was obtained when the loading of borate were less than $5 \mathrm{wt} \%$ based on $\mathrm{B}_{2} \mathrm{O}_{3}$, whereas the conversion and selectivity remained unchanged with further increase in borate loading exceeding $5 \mathrm{wt} \%$. This result was significantly different from the volcanic distribution of dehydrogenation selectivity over the phosphate modified CNTs. Borate modification was more selective than phosphate towards the blockage of defects on the CNTs. The modification with heteroatoms can selectively cover $\mathrm{C}=\mathrm{O}$ groups and block defects, which allows its use as a modulator of defects and oxygen-containing functional groups on the carbon materials. This regulates the distribution of active sites and related catalytic targets $[63,137]$. The defects can also act as nuclei for the formation of soot, which leads to the deactivation of catalysts. It was found by TEM and Raman spectroscopy measurements that the chemical oxidative treatment partially removes amorphous carbon from the surface of CNTs. The intensity ratio $I_{\mathrm{D}} / I_{\mathrm{G}}$ continuously decreased after the thermal treatment at 1300 and $1700{ }^{\circ} \mathrm{C}$, indicating the rearrangements of the carbon atoms to reduce structural defects and to improve the graphitization of the CNTs. Therefore, the coke tolerance and combustion tolerance of CNTs were improved [138].

Although some fruitful results have been obtained, the efficient controlling and measuring of surface defects, edges, and vacancies, the effect of surface structures tuning as well as the mechanism for their effect on the catalytic performance in DDH reaction still remain to be solved.

\subsection{2. $\mathrm{DDH}$ reaction}

Different from ODH, there is neither the over-oxidation of hydrocarbons and the olefins nor the combustion of carbocatalysts. Ketone-type functional groups anchored on the defects/edges/vacancies are active for $\mathrm{C}-\mathrm{H}$ activation. Although the oxygen functional groups are desorbed by annealing, the defects, edges, and vacancies can serve as catalytic active sites for the $\mathrm{C}-\mathrm{H}$ bond activation of hydrocarbons to olefins through the DDH reaction.

Structural defects and surface oxygen functionalities can be tuned by changing the hybridization state of carbon. Su and coworkers [82] prepared a series of nanodiamond derivatives with different $s p^{2}$ carbon contents (estimated from electron energy loss spectroscopy spectra) by an annealing treatment. The intensity ratio of $I_{\mathrm{D}} / I_{\mathrm{G}}$ is normally used to qualitatively estimate the surface defect degree of $s p^{2}$-bonded carbon materials. From their results, during elevated annealing treatment, the $I_{\mathrm{D}} / I_{\mathrm{G}}$ ratio rose and then decreased with a maximum $I_{\mathrm{D}} / I_{\mathrm{G}}$ value for the ND-1100 sample. They proposed that the defect degree increased with increasing fraction of $s p^{2}$ carbon at the early graphitization stage, and then it reached the maximum defectiveness on the interface of the $s p^{2} / s p^{3}$ composite composed of a diamond core with a thin, defective, curved graphene outer shell with a certain ratio of mixed carbon. However, the formation of a well-ordered OLC shell after further increase in annealing temperature caused a significant decrease in structural defects. From the reaction results for the DDH of propane, the catalytic performance increased as the annealing temperature was increased. It reached a maximum value as the annealing temperature reached up to $1100{ }^{\circ} \mathrm{C}$, and $10.6 \%$ steady state conversion with $90 \%$ propene selectivity over the ND-1100 (prepared by annealing at $1100{ }^{\circ} \mathrm{C}$ ) was observed. However, the decreased surface oxygen content from $5.5 \%(9.7 \%$ for parent ND) to $2.0 \%$ as the annealing temperature rose from 550 to $1100{ }^{\circ} \mathrm{C}$ had been identified by XPS. The normalized propane consumption rate based on ketonic carbonyl oxygen increased from $6.8 \times 10^{-4}$ to $1.4 \times 10^{-3} \mathrm{~s}^{-1}$ was observed as the annealing temperature rose from 550 to 1100 ${ }^{\circ} \mathrm{C}$, suggesting that besides ketonic carbonyl groups, the defects/vacancies may be responsible for the DDH reaction. The role in the catalytic DDH reaction of surface structural defects was further investigated by cyclic DDH reaction followed by temperature programmed desorption. They found that once the basic oxygen functional groups were desorbed, the bare defects/vacancies were responsible for the activation of the $\mathrm{C}-\mathrm{H}$ bond of the hydrocarbon.

The defect/vacancies of the carbon host also can play the role of anchorage sites for the guest, and therefore the hybrid with the guest dispersed anchored on the host can be prepared. High-resolution TEM analysis indicated the presence of vacancies and defects on the few-layer graphene (FLG) surface which can provide anchorage sites for the active phase dispersion and stabilization. The ND/FLG hybrid exhibited a high and relative- 
ly stable catalytic performance in the DDH of ethylbenzene compared to the other carbon-based and doped iron industrial catalysts. The DDH activity per weight ND was 4 times higher than on unsupported ND, ascribed to the dispersion of ND particles on the FLG surface leading to a higher effective surface area, graphitization of the surface composite during the DDH reaction and synergistic effects of the hybrid carbon nano-structured materials. The high density of surface defects and vacancies on FLG was responsible for the good dispersion and anchorage of ND [45]. The role of defects and vacancies in a directly promoting effect was not involved.

It was confirmed that increased structural defects benefited the DDH reaction. We developed a facile and sustainable glucose hydrothermal strategy approach for efficiently increasing defectiveness of CNTs, besides tuning the morphology and surface chemistry [84]. A combination of HRTEM and Raman spectroscopy clearly identified the increased defects by this approach. As a result, the developed N-doped CNTs with increased defects showed significantly enhanced catalysis in the DDH of ethylbenzene to styrene. The developed strategy including the glucose hydrothermal treatment and subsequently pyrolysis in the presence of melamine can be extended to the fabrication of novel N-doped mesoporous carbon (M-Glu-CNT). A significantly enhanced catalytic performance in DDH was also obtained. The catalytic performance was strongly dependent on its microstructure and surface chemistry. Then we developed a facile two-step method including air activation and subsequent pyrolysis of melamine to prepare nitrogen-doped CNT with enriched structural defects and surface ketonic $\mathrm{C}=0$ groups. Besides, the air activation process can remove the formed $\mathrm{CN}_{x}$ layers from melamine pyrolysis [129]. It was found that the fabricated N-doped CNT in this work showed remarkably improved catalytic performance in the DDH of ethylbenene. By correlating the reaction results to the catalyst nature, the superior catalytic performance was ascribed to the increased catalytic active sites containing structural defects and ketonic $\mathrm{C}=\mathrm{O}$, as well as the enhanced accessibility of active sites to the reactants by the elimination of the $\mathrm{CN}_{x}$ layers coated on the CNT walls.

The promoting effect by surface structural defectiveness has been confirmed to be an efficient strategy for the development of carbocatalysts with excellent catalytic performance in the DDH reaction. How to strengthen the promoting effect? Which approaches are better with respect to efficiency, energy, environment, and cost? Is it possible to have simultaneous $\mathrm{N}$-doping and defects formation, since $\mathrm{N}$-doping can efficiently promote the catalytic performance in DDH? These are some interesting questions to be answered.

In order to answer these questions, in our ACM research group, we developed some interesting approaches. It was previously reported that the introduction of guanidine nitrate in the process of N-doping of CNTs through the pyrolysis of melamine efficiently enhanced the surface defectiveness on CNT walls, confirmed by the HRTEM and Raman spectroscopy characterization. The prepared N-doped CNTs with enriched defects (G-M-CNT) demonstrated superior catalytic performance in the DDH of ethylbenzene compared to the parent CNT and to the N-doped CNT prepared by the same process as that for G-M-CNT except for the absence of guanidine nitrate [88]. By employing the above guanidine nitrate assisted melamine pyrolysis method, N-doped CNTs with enriched defects were obtained. But the excess of two reagents was required, and the defectiveness was also required to be further improved. Recently, research on the supramolecular chemistry of the melamine-cyanuric acid assembly (MCSA) has been increasing since its discovery in 1990. The improved catalytic activity of carbon nitride derived from MCSA upon heating at low or medium temperature has been demonstrated. Owing to the higher 0 atom content in MCSA, it undergoes explosive decomposition on heating at high temperature. We envisioned that N-doping and the enrichment of structural defects would occur simultaneously when MCSA was used as N precursor, allowing the fabrication of structural defect-rich $\mathrm{N}$-doped carbonaceous materials. Therefore, we explored this issue. From our results, a facile and scalable approach for fabricating structural defect-rich nitrogen-doped carbon nanotubes (MCSA-CNTs) through the explosive decomposition of an MCSA assembly was presented [83]. In comparison to pristine carbon nanotubes, MCSA-CNT exhibited significantly enhanced catalytic performance in the DDH reaction of ethylbenzene, demonstrating the potential for metal-free clean and energy-saving styrene production.

The results illustrated that it was feasible to simultaneous fabricate N-doped carbon catalysts with enriched defects for the DDH reaction by employing an appropriate compound as both N-precursor and explosive material. Moreover, the increased surface oxygen is also favourable for the DDH reaction. It can be proposed that the selection of more efficient and lower cost chemicals is of practical significance. The further work presented a facile one-step strategy for simultaneously $\mathrm{N}$-doping and structural defects increasing of $\mathrm{N}$-doped carbon nanotube (HN-CNT) through the explosive decomposition of hexamethylenetetramine (HTA) nitrate. The as-synthesized HN-CNT demonstrated 1.64 and 2.19 times higher steady state styrene rate with $98.5 \%$ selectivity towards styrene for the direct dehydrogenation (DDH) over that of the parent CNT and $\mathrm{H}-\mathrm{CNT}$ prepared by the similar pyrolysis procedure to that for the HN-CNT except for replacing HTA nitrate with HTA [130]. Furthermore, a facile and low cost one-step strategy by employing melamine nitrate as $\mathrm{N}, \mathrm{O}$-precursor and explosive compound was developed to synthesize O,N-doped CNTs with increased structural defects and enriched surface ketonic $\mathrm{C}=\mathrm{O}$ groups (MN-CNT), which demonstrated unexpected catalytic performance in the DDH of ethylbenzene for styrene production with clean and energy saving features. In comparison to HN-CNT, the MN-CNT demonstrated better catalytic performance.

For the DDH reaction, since no over-oxidation of the substrate or combustion of carbon catalyst exists, the development of new and efficient approach for strengthening defects, graphitic edges, and vacancies is a promising research domain. Moreover, although the promoting effect of defects, graphitic edges, and vacancies is indisputable, quantitative research on this promoting effect and the mechanism remains to be done. 


\section{Modulating of the surface chemistry}

The surface chemistry mainly involves the elemental components and their chemical state, which decide the properties of chemical active sites and subsequently the catalytic performance. Some post treatment approaches like doping with heteroatoms can be employed as a potentially useful way to efficiently adjust the surface chemistry. In previous reviews [4,5] the authors have suggested that XPS, TPD, FT-IR, chemical titration, elemental analysis, microcalorimetric analysis and DFT calculation were powerful tools to study the surface chemistry of carbocatalysts. In this section, we review the advances in the method for tuning surface chemistry and the role in regulating the catalytic performance of activity, selectivity, and stability of carbocatalysts in the ODH and DDH of hydrocarbons to olefins. The change of types and morphology of carbocatalysts can adjust the surface chemistry, but these issues are excluded from this review. Here, the special approach for efficiently tuning surface chemistry through post treatment is considered.

\subsection{ODH Reaction}

Among the different oxygen-containing groups, the ketonic carbonyl groups were identified to be active for the ODH reaction. The introduction of electron-rich heteroatoms can adjust the electronic properties of oxygen functionalities and also modulate the defectiveness, which significantly affects the activity, selectivity (over-oxidation) and stability (combustion of carbocatalysts). Through oxidative treatment and heteroatom-doping, the surface chemical properties of carbon materials including surface elemental component and state can be directly or indirectly regulated, which in turn adjusts their catalytic performance in the ODH reaction [138-146].

The oxidative treatment by a gas or liquid phase approach is a direct method for adjusting the active sites for the ODH reaction [138-143]. AC is a low cost, high surface porous carbon material. Many years ago, the oxidation treatment of $\mathrm{AC}$ and its application in ODH was reported $[103,139,140]$. Pereira et al. [139] and Velásquez et al. [140] investigated the oxidative treatment of $\mathrm{AC}$ in a gas $\left(5 \% \mathrm{O}_{2}\right.$ at $435{ }^{\circ} \mathrm{C}$ for different times) or liquid phase $\left(\mathrm{HNO}_{3}, \mathrm{H}_{2} \mathrm{O}_{2}\right)$ method, and the influence of the treatment on the surface chemistry and catalytic performance in the ODH of ethylbenzene and isobutene to their corresponding olefins. TPD was used to probe the surface oxygen groups. It was found that the gas oxidative treatment efficiently increased the amount of carbonyl and quinone groups but liquid oxidation led to an increase in carboxylic group, identified by TPD measurement. As a result, the modified AC by the oxidative treatment in the gas phase exhibited a much higher catalytic activity with comparable selectivity in comparison the one modified by liquid oxidation. Kozłowski and coworkers [103] comprehensively compared the effect of various oxidants like $\mathrm{H}_{2} \mathrm{O}_{2}$, $\left(\mathrm{NH}_{4}\right)_{2} \mathrm{~S}_{2} \mathrm{O}_{8}, \mathrm{HNO}_{3}, \mathrm{CH}_{3} \mathrm{COOOH}$ (peroxyacetic acid), air used in the oxidative treatment of $\mathrm{AC}$ on the surface chemistry and catalytic performance in $\mathrm{ODH}$ of isobutane. The results of TPD, elemental analysis and $\mathrm{N}_{2}$ adsorption revealed that the surface oxygen content and type of oxygen groups as well as texture were strongly affected by the type of oxidant. By correlating with reaction results, the catalytic performance was noted as dependent on not only oxygen content but also the type of oxygen groups. However, there was no correlation between surface area and catalytic performance of the modified AC catalysts. Moreover, the gas and liquid oxidative method were also used in the modification of carbon nanotubes, ND, and mesoporous carbon $[103,138,141-143]$. The created active sites by oxidative treatment of the carbon materials and the subsequent promotion of the catalysis in ODH were further identified. It is worth mentioning that Zhang and coworkers [65] developed a hydrothermal method of defect-functionalized carbon nanotube to regulate surface oxygen groups. The catalyst exhibited good catalytic performance in the ODH of ethylbenzene in the presence of $\mathrm{CO}_{2}$.

Doping by heteroatoms is also an efficient approach for regulating the surface chemistry of carbocatalysts. The effect of $\mathrm{N}$, $\mathrm{P}$, and $\mathrm{B}$ doping on the surface chemical properties and catalytic performance in ODH has been investigated $[46,59,63,66,80$, 144-146]. Chen et al. [59] found that graphitic nitrogen has a determining effect on enhancing the catalytic performance of CNTs in the ODH reaction through reducing the activation energy by speeding up dissociative adsorption and activation of molecular oxygen. Figueiredo and coworkers [66] prepared carbon xerogels with different nitrogen contents, and found that the catalytic activity of synthesized carbon xerogels increased as the nitrogen content was increased. $\mathrm{N}$-doping is favourable for high activity, but it may lead to depressed selectivity due to over-oxidation of hydrocarbons. Moreover, the $\mathrm{N}$-doping can also produce structural defects [89], which also may lower the selectivity to olefin production by over-oxidation besides the stability of carbon catalysts by carbon combustion.

The surface chemistry and catalytic performance of carbocatalysts can also be regulated by $\mathrm{B}$ and $\mathrm{P}$ doping [46,63,80,144-146]. Dai and coworkers compared CNF and CNF-supported phosphoric oxide as the catalysts for the ODH of propane [144]. They found CNF itself was an effective catalyst for $\mathrm{ODH}$, but a high propene yield can only be achieved at a high reaction temperature, which would cause CNF gasification. CNF-supported phosphoric oxide can operate at $500{ }^{\circ} \mathrm{C}$ without gasification. The role of $\mathrm{P}$ in increasing the gasification-resistance of CNF at high temperature was identified. The defect feature and oxygen-containing groups on CNTs can be regulated by $\mathrm{P}$ doping, which resulted in increasing selectivity through suppressing the over-oxidation of hydrocarbons [46,63]. García-Bordejé and coworkers [145] prepared B and P doped CNFs by an ex situ approach and N-doped CNF by in situ method using ethylenediamine as the $\mathrm{N}$ - and $\mathrm{C}$-precursor, and investigated the roles of heteroatom-doping in adjusting the surface chemistry and catalytic performance of the CNFs in the ODH of propane. The N-doped CNF exhibited the highest activity but the worst selectivity for the ODH reaction of propane. They found that the doping of CNFs with B or P efficiently enhanced the selectivity to propene. However, a decreased propane conversion over B-doped CNF was observed, ascribed to the blockage of reactant activation sites by an excess of $\mathrm{B}$. The $\mathrm{P}$ 
doping brought about enhanced selectivity compared to B doping The doping using a triphenylphosphine precursor was found to exhibit higher propene selectivities than doping using ammonium phosphate, which was ascribed to the different $\mathrm{P}$ species on CNFs formed from different $\mathrm{P}$ precursors. The increased stability of CNFs towards combustion of carbon materials in the presence of oxygen by B or P doping was also confirmed. Moreover, it was found that phosphate preferentially reacted with the phenol groups initially present on the surface of carbon materials, and then it selectively blocked the defect sites that lead to $\mathrm{CO}_{x}$ formation with increased propene selectivity. However, no influence on the nature of the active sites (ketonic carbonyl groups) during this process was detected [79]. It was further observed that borate modification was more selective than phosphate modification for the blockage of defects and the inhibition of combustion reaction on the CNTs supported by XPS, TPD and TPO [137].

Schwartz and coworkers [146] investigated the P-doping of graphitic mesoporous carbon and its use in the ODH of isobutane. It was found that $\mathrm{P}$ doping can efficiently increased the selectivity for isobutene production via the ODH reaction of isobutene. However, it did not change the nature of the active sites but interfere with the availability of the sites. Su and coworkers [80] found that B doping can change surface oxygen-containing groups through interaction between $\mathrm{B}$ atom and the carbon surface, and therefore increased the selectivity for the ODH of propane. The new insight into the mechanism of interaction between the heteroatom and carbon surface, as well as their influence on the catalytic performance in ODH reaction can provide guidance for the rational modification of nanocarbons.

\subsection{DDH reaction}

As mentioned above, unlike the ODH reaction, there is neither overoxidation of hydrocarbons nor carbon combustion over the carbocatalysts. More defects are favourable for high activity but they don't depress selectivity. Therefore, although it was proposed that the surface oxygen-containing groups could be affected by $\mathrm{B}$ doping [80], many researches were focused on $\mathrm{N}$ doping but not on $\mathrm{B}, \mathrm{P}$ doping, since the main role of $\mathrm{B}$ or $\mathrm{P}$ doping is to improve the selectivity and stability of the carbocatalysts for ODH reactions by suppressing the over-oxidation of hydrocarbons and strengthening the combustion-tolerance of carbon materials. It was established that the oxidative treatment can increase active sites, and therefore improve the catalytic performance in the dehydrogenation reaction of hydrocarbons. The role of the oxidative treatment in regulating surface chemistry of the carbon materials for the DDH reaction is similar to that for the ODH reaction [91]. Therefore, herein we will not focus on the tuning of the surface chemistry of carbocatalysts for DDH by routine oxidative treatment.

$\mathrm{N}$-doping does not always benefit the ODH reaction due to the possible over-oxidation of hydrocarbons and carbon combustion. However, it may always benefit the DDH reaction because no oxygen exists in the DDH reaction systems. By using hexamethylenetetramine as carbon nitride precursor, mesoporous graphitic carbon nitride nanorods with $9.3-23 \mathrm{wt} \%$ of high $\mathrm{N}$ content were prepared. The mesoporous carbon nitride exhibited much higher catalytic activity and selectivity for the DDH of ethylbenzene than mesoporous carbon. It was proposed that the increased electron density and basic properties for $\mathrm{C}=\mathrm{O}$ resulting from the incorporation of nitrogen atom into the carbon matrix efficiently promoted the DDH to styrene but depressed the formation of cracking side products like benzene and toluene. Moreover, the $\mathrm{N}$-doped mesoporous carbon has more defects, which can activate $\mathrm{C}-\mathrm{H}$ bond and promote the DDH reaction [89]. Su et al. [115] also exhibited the promoting effect of $\mathrm{N}$-doping of mesoporous carbon nanospheres on the DDH of ethylbenzene.

Because surface ketonic carbonyl group, defects, edges, and vacancies are active sites for the DDH reaction, as well as the introduction of $\mathrm{N}$ into the carbon matrix to efficiently promote DDH reaction, to develop a facile and efficient strategy for fabricating $\mathrm{N}, \mathrm{O}$ dual doped carbon materials with enriched defects, edges, and vacancies is highly desirable for the DDH reaction. Certainly, the morphology, size and texture should be taken into account while we explore the tuning of surface chemistry. That is to say, the role of tuning the surface chemistry is mainly to regulate the properties of the active sites including amount, distribution, and electronic properties. In our previous work [84,129], we used the introduction of a pre-treatment process like controlled glucose hydrothermal treatment or prior air activation before $\mathrm{N}$-doping by pyrolysis of melamine. The XPS results identified that the oxygen content and chemical state were efficiently adjusted, and therefore their catalytic performance in DDH was subsequently tuned. Furthermore, the facile one-step strategy for tuning the surface chemistry and surface structure was developed in our research group $[83,129,130]$. As a one-pot method, the choice of an appropriate chemical is required to obtain excellent $\mathrm{N}$-doped carbocatalysts with enriched ketonic carbonyl groups and defects, edges and/or vacancies. Primarily, the melamine-cyanuric acid supramolecular assembly was employed as $\mathrm{O}, \mathrm{N}$-precursor and the explosive chemical to produce the above materials [83]. N-doping and defect-forming were simultaneously completed, which exhibited significantly enhanced catalytic performance in comparison to the parent CNT and the modified CNT by using melamine, cyanuric acid, and the mixture of melamine and cyanuric acid. However, we did not see an increase in surface oxygen-containing groups.

From the above analysis, the surface ketonic carbonyl groups are the main active sites for DDH reaction. Therefore, our previous work [83] inspired us to see whether we can find a chemical for simultaneous N, $\mathrm{O}$ dual doping and defect forming. Melamine is a common $\mathrm{N}$ precursor, and an organic nitrate like guanidine nitrate are explosive compounds which can produce defect and introduce $\mathrm{O}$ atom [88]. We envisioned that the appropriate organic nitrate can introduce $\mathrm{N}, \mathrm{O}$ and increase defects. Therefore, we explored the possibility of employing melamine nitrate [130] and hexamethylenetetramine nitrate [129] as N,O-precursor and defect-forming reagent. It was found that besides the removing of surface formed $\mathrm{CN}_{x}$ layers 
from the organic motifs like melamine and hexamethylenetetramine, both of them can efficiently introduce $\mathrm{N}$ and $\mathrm{O}$ atoms as well as increase structural defects on the CNT surface, and therefore give significantly improved catalytic performance in the DDH reaction of ethylbenzene. The O,N-doped CNT with enriched defects by the explosive pyrolysis of melamine nitrate had more surface $\mathrm{C}=0$ groups than that on the modified CNT by hexamethylenetetramine nitrate. However, the latter had more structural defects. As a DDH catalyst, both of these exhibited outstanding catalytic performance, although resulting from different catalyst features. The developed one-step strategy for simultaneous $\mathrm{O}, \mathrm{N}$-doping and defects forming may pave a new avenue for synthesizing other highly efficient carbocatalysts for different organic transformations.

\section{Conclusions}

Carbocatalysis presents a new alternative to the traditional metal catalytic process in different transformations. The design, fabrication and tuning of carbocatalysts have become a frontier domain in catalysis and materials science. This review highlighted the state of the art and future challenge of improvement in the DDH and ODH catalytic performance of carbocatalysts by modulating the microstructure and surface chemistry. The catalytic behaviour of carbocatalysts is decided by the properties of the active sites and their accessibility to reactants, which are significantly dependent on the microstructure and surface chemistry. The shape, size, and texture of the carbocatalyst significantly affect the accessibility of active sites for the dehydrogenation of hydrocarbons. The surface chemistry and the surface structures including defect, graphitic edge and vacancies notably affect the properties of catalytically active sites. Surface defects, graphitic edge and vacancies are active for $\mathrm{C}-\mathrm{H}$ bond activation, therefore they favor the DDH reaction. However, they lead to the over-oxidation side reaction of hydrocarbons and combustion of carbon materials under ODH reaction conditions. The appropriate amounts of surface defects, graphitic edges and vacancies are essential for the ODH reaction but not that more is always better. As for the manipulating of the microstructure, while we think of the accessibility of active sites, the stability of the structure is also taken into account.

Owing to high activity of carbocatalysts for the ODH reaction, many fruitful results have been achieved in this area. However, the depressed selectivity from over-oxidation and unsatisfactory stability due to the combustion of carbon materials are challenges before the industrial application in olefin production by carbocatalyst-mediated ODH reaction of hydrocarbons. Besides, the shaping of the carbocatalyst is needed in order to be suitable for use in large scale fixed bed reactors. Heteroatoms like B, P, etc. for doping are an efficient method for improving selectivity and stability. Moreover, an efficient handling method should be developed to avoid the potential explosion of the mixture of hydrocarbons and oxygen, and a mild oxidant like $\mathrm{CO}_{2}, \mathrm{NO}_{x}$, etc. may be a good choice. Of course, when a soft oxidant is used, the key point would be not only the selectivity and stability but also the activity. The carbon materials mediated DDH of hydrocarbons under oxidant- and steam-free conditions was demonstrated to be a promising candidate for olefin production for the high selectivity and stability. However, the further improvement in catalytic activity is highly desirable. Moreover, like ODH, the shaping of the carbocatalysts is also an important issue for the possible industrial application of the carbocatalysts for the DDH reaction. Therefore, the shaping of carbocatalysts is an inevitable issue, and the design and fabrication of macroscopic carbon structures are interesting research directions for industrial applications.

This review has presented the advances in the tuning of microstructure and surface chemistry as well as their influence on the catalytic performance in the ODH and DDH reactions. Although fruitful results have been achieved by many research groups, further work on the improvement in the catalytic performance including activity, selectivity and stability through the regulating of microstructure and surface chemistry is highly desirable. The authors hope to demonstrate that the manipulating of microstructure and surface chemistry is a powerful tool for tuning catalytic performance in dehydrogenation. Hopefully it provides inspiration for rational design, synthesis and modulating of carbocatalysts for dehydrogenation reactions including the ODH and DDH of hydrocarbons to olefins, as well as for other organic transformations. It should be pointed out that because there are previous reviews [4-6], the details for XPS, TPD, FT-IR, titration, elemental analysis, calorimetry, and theoretical calculation results published by experts in the field have not been included in this paper, although they are very important for developing highly efficient carbon catalysts. Moreover, it is worth pointing out that the role of residual metals on the carbon materials, and even the ones catalyzing the formation of the carbon materials shall be addressed in future work. Furthermore, although the basic concepts for the dehydrogenation of hydrocarbons to olefins over carbocatalysts through the ODH and DDH processes have been well established, the in-depth understanding in the active sites, fundamental mechanism, kinetic studies, as well as many engineering issues must be fully addressed before possible applications. In our opinion, although a soft oxidant like $\mathrm{CO}_{2}$ can be used in ODH over metal based catalysts, molecular oxygen is required for high activity for the carbon-mediated ODH process. The DDH over carbocatalysts under steam- and oxidant-free conditions has huge industrial potential due to the elimination of structural damage in the absence of molecular oxygen. From the references, the nanodiamond-based catalysts, especially the monolithic nanodiamond-based catalysts, exhibited excellent selectivity and stability for $\mathrm{DDH}$, and can be considered as a promising candidate for the DDH reaction for styrene production [147-149]. However, the improvement in the catalytic activity of nanodiamond-based catalysts is still required for industrial application in the styrene production with high-efficient, energy-saving, and clean feature. How to improve the catalytic activity of supported nanodiamond monolithic catalysts will be addressed in the future.

\section{References}

[1] J. J. H. B. Sattler, J. Ruiz-Martinez, E. Santillan-Jimenez, B. M. 


\section{Graphical Abstract}

Chin. J. Catal., 2016, 37: 644-670 doi: 10.1016/S1872-2067(15)61065-8

Modulating the microstructure and surface chemistry of carbocatalysts for oxidative and direct dehydrogenation: A review

Zhongkui Zhao*, Guifang Ge, Weizuo Li, Xinwen Guo, Guiru Wang Dalian University of Technology

This review presents the state of the art in the manipulating of the microstructure and surface chemistry of carbocatalysts for the oxidative dehydrogenation and direct dehydrogenation of hydrocarbons to olefins.

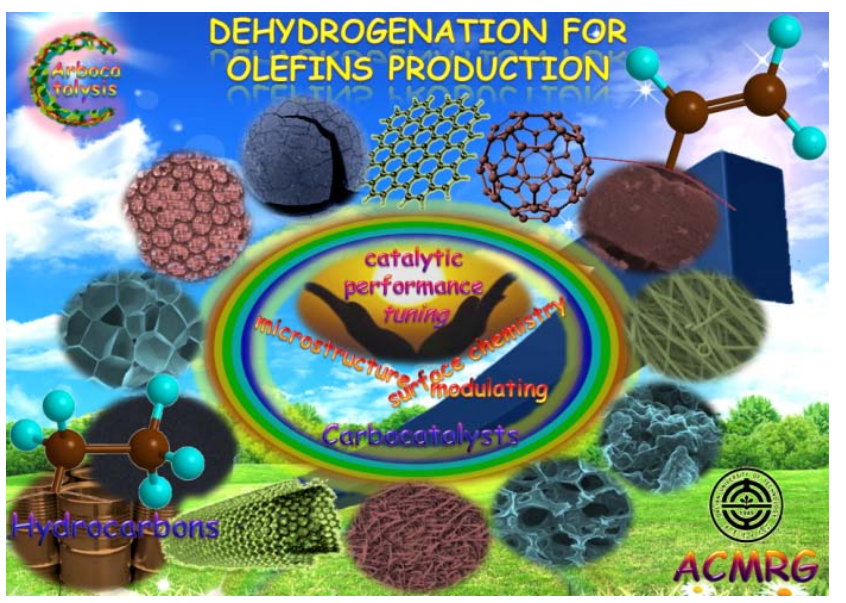

Weckhuysen, Chem. Rev., 2014, 114, 10613-10653.

[2] C. A. Carrero, R. Schlögl, I. E. Wachs, R. Schomaecker, ACS Catal., 2014, 4, 3357-3380.

[3] F. Cavani, F. Trifiro, Appl. Catal. A, 1995, 133, 219-239.

[4] W. Qi, D. S. Su, ACS Catal., 2014, 4, 3212-3218.

[5] D. Chen, A. Holmen, Z. J. Sui, X. G. Zhou, Chin. J. Catal, 2014, 35 , 824-841.

[6] L. M. Madeira, M. F. Portela, Catal. Rev.-Sci. Eng., 2002, 44, 247-286.

[7] M. S. Chen, M. C. White, Science, 2010, 327, 566-571.

[8] Y. H. Li, S. Das, S. L. Zhou, K. Junge, M. Beller, J. Am. Chem. Soc., 2012, 134, 9727-9732.

[9] Q. S. Gao, C. Giordano, M. Antonietti, Angew. Chem. Int. Ed., 2012, $51,11740-11744$.

[10] D. R. Dreyer, C. W. Bielawski, Chem. Sci., 2011, 2, 1233-1240.

[11] C. L. Su, K. P. Loh, Acc. Chem. Res., 2013, 46, 2275-2285.

[12] X. Y. Sun, R. Wang, D. S. Su, Chin. J. Catal., 2013, 34, 508-523.

[13] A. Schaetz, M. Zeltner, W. J. Stark, ACS Catal., 2012, 2, 1267-1284.

[14] M. A. Patel, F. X. Luo, M. R. Khoshi, E. Rabie, Q. Zhang, C. R. Flach, R. Mendelsohn, E Garfunkel, M. Szostak, H. He, ACS Nano, 2016, 10, 2305-2315.

[15] W. Qi, W. Liu, B. S. Zhang, X. M. Gu, X. L. Guo, D. S. Su, Angew. Chem. Int. Ed., 2013, 52, 14224-14228.

[16] Y. J. Gao, G. Hu, J. Zhong, Z. J. Shi, Y. S. Zhu, D. S. Su, J. G. Wang, X. H. Bao, D. Ma, Angew. Chem. Int. Ed., 2013, 52, 2109-2113.

[17] S. P. Pitre, C. D. McTiernan, H. Ismaili, J. C. Scaiano, J. Am. Chem. Soc., 2013, 135, 13286-13289.

[18] Y. Wang, X. C. Wang, M. Antonietti, Angew. Chem. Int. Ed., 2012, 51, 68-89.

[19] J. Bedia, R. Ruiz-Rosas, J. Rodríguez-Mirasol, T. Cordero, AIChE J., 2010, 56, 1557-1568.

[20] P. J. Ji, H. S. Tan, X. Xu, W. Feng, AIChE J., 2010, 56, 3005-3011.

[21] K. Schwinghammer, B. Tuffy, M. B. Mesch, E. Wirnhier, C. Martineau, F. Taulelle, W. Schnick, J. Senker, B. V. Lotsch, Angew. Chem. Int. Ed., 2013, 52, 2435-2439.

[22] M. Younessi-Sinaki, F. Hamdullahpur, AIChE J., 2014, 60, 2228-2234.
[23] M. Shalom, S. Inal, C. Fettkenhauer, D. Neher, M. Antonietti, J. Am. Chem. Soc., 2013, 135, 7118-7121.

[24] Y. S. Jun, E. Z. Lee, X. C. Wang, W. H. Hong, G. D. Stucky, A. Thomas, Adv. Funct. Mater., 2013, 23, 3661-3667.

[25] Y. Zheng, Y. Jiao, Y. L. Ge, M. Jaroniec, S. Z. Qiao, Angew. Chem. Int. Ed., 2013, 52, 3110-3116.

[26] Y. Zhao, L. J. Yang, S. Chen, X. Z. Wang, Y. W. Ma, Q. Wu, Y. F. Jiang, W. J. Qian, Z. Hu, J. Am. Chem. Soc., 2013, 135, 1201-1204.

[27] K. Ai, Y. L. Liu, C. P. Ruan, L. H. Lu, G. Q. Lu, Adv. Mater., 2013, 25, 998-1003.

[28] H. Wang, K. Sun, F. Tao, D. J. Stacchiola, Y. H. Hu, Angew. Chem. Int. Ed., 2013, 52, 9210-9214.

[29] I. V. Lightcap, P. V. Kamat, Acc. Chem. Res., 2013, 46, 2235-2243.

[30] R. Schlögl, Adv. Catal., 2013, 56, 103-185.

[31] S. Navalon, A. Dhakshinamoorthy, M. Alvaro, H. Garcia, Chem. Rev., 2014, 114, 6179-6212.

[32] Y. Wang, X. C. Wang, M. Antonietti, Angew. Chem. Int. Ed., 2012, 51, 68-89.

[33] L. R. Radovic, C. Mora-Vilches, A. J. A. Salgado-Casanova, Chin. J. Catal., 2014, 35, 792-797.

[34] C. C. Huang, C. Li, G. Q. Shi, Energy Environ. Sci., 2012, 5, 8848-8868.

[35] X. K. Kong, C. L. Chen, Q. W. Chen, Chem. Soc. Rev., 2014, 43, 2841-2857.

[36] D. W. Wang, D. S. Su, Energy Environ. Sci., 2014, 7, 576-591.

[37] C. Ampelli, S. Perathoner, G. Centi, Chin. J. Catal., 2014, 35, 783-791.

[38] X. Y. Sun, R. Wang, D. S. Su, Chin. J. Catal., 2013, 34, 508.

[39] D. S. Su, J. Zhang, B. Frank, A. Thomas, X. C. Wang, J. Paraknowitsch, R. Schlögl, ChemSusChem, 2010, 3, 169-180.

[40] J. J. Vilatela, D. Eder, ChemSusChem, 2012, 5, 456-478.

[41] J. Zhu, A. Holmen, D. Chen, ChemCatChem, 2013, 5, 378-401.

[42] D. S. Su, S. Perathoner, G. Centi, Chem. Rev., 2013, 113, 5782-5816.

[43] A. Guerrero-Ruiz, I. Rodriguez-Ramos, Carbon, 1994, 32, 23-29.

[44] M. F. R. Pereira, J. M. Orfao, J. L. Figueiredo, Appl. Catal. A, 1999, 184, 153-160.

[45] H. Ba, S. Podila, Y. Liu, X. Mu, J.-M. Nhut, V. Papaefthimiou, S. Zafei- 
ratos, P. Granger, C. Pham-Huu, Catal. Today, 2015, 249, 167-175.

[46] J. Zhang, X. Liu, R. Blume, A. Zhang, R. Schlögl and D. S. Su, Science, 2008, 322, 73-77.

[47] J. Zhang, D. S. Su, R. Blume, R. Schlögl, R. Wang, X. Yang, A. Gajović, Angew. Chem. Int. Ed., 2010, 49, 8640-8644.

[48] S. J. Guo, S. D. Zhang, S. Sun, Angew. Chem. Int. Ed., 2013, 52, 8526-8544.

[49] I. Lee, F. Delbecq, R. Morales, M. A. Albiter, F. Zaera, Nat. Mater., 2009, 8, 132-138.

[50] R. Krishna, Chem. Soc. Rev., 2012, 41, 3099-3118.

[51] F. Tao, Chem. Soc. Rev., 2012, 41, 7977-7979.

[52] Y. Li, W. Shen, Chem. Soc. Rev., 2014, 43, 1543-1574.

[53] W. X. Huang, Y. X. Gao, Catal. Sci. Technol., 2014, 4, 3772-3784.

[54] D. F. van der Vliet, C. Wang, D. Tripkovic, D. Strmcnik, X. F. Zhang, M. K. Debe, R. T. Atanasoski, N. M. Markovic, V. R. Stamenkovic, Nat. Mater., 2012, 11, 1051-1058.

[55] J. L. Gong, Chem. Rev., 2011, 112, 2987-3054.

[56] C. C. Lin, Y. Guo, J. Vela, ACS Catal., 2015, 5, 1037-1044.

[57] J. G. Yu, J. X. Low, W. Xiao, P. Zhou, M. Jaroniec, J. Am. Chem. Soc., 2014, 136, 8839-8842.

[58] Y. Zhao, C. Eley, J. P. Hu, J. S. Foord, L. Ye, H. W. He, S. C. E. Tsang Angew. Chem. Int. Ed., 2012, 51, 3846-3849.

[59] C. L. Chen, J. Zhang, B. S. Zhang, C. L. Yu, F. Peng, D. S. Su, Chem. Commun., 2013, 49, 8151-8153.

[60] X. D. Hu, Y. T. Wu, H. R. Li, Z. B. Zhang, J. Phys. Chem. C, 2010, 114, 9603-9607.

[61] S. Mao, B. Li, D. S. Su, J. Mater. Chem. A, 2014, 2, 5287-5294.

[62] H. Xie, Z. L. Wu, S. H. Overbury, C. D. Liang, V. Schwartz, J. Catal., 2009, 267, 158-166.

[63] R. Huang, H. Y. Liu, B. S. Zhang, X. Y. Sun, C. H. Liang, D. S. Su, B. N. Zong, J. F. Rong, ChemSusChem, 2014, 7, 3476-3482.

[64] G. K. P. Dathar, Y. T. Tsai, K. Gierszal, Y. Xu, C. D. Liang, A. J. Rondinone, S. H. Overbury, V. Schwartz, ChemSusChem, 2014, 7, 483-491.

[65] R. C. Rao, M. Yang, Q. Ling, C. S. Li, Q. Y. Zhang, H. X. Yang, A. M. Zhang, Catal. Sci. Technol., 2014, 4, 665-671.

[66] I. Pelech, O. S. G. P. Soares, M. F. R. Pereira, J. L. Figueiredo, Catal Today, 2015, 249, 176-183.

[67] G. Mestl, N. I. Maksimova, N. Keller, V. V. Roddatis, R. Schlögl, Angew. Chem. Int. Ed., 2001, 40, 2066-2068.

[68] T. J. Zhao, W. Z. Sun, X. Y. Gu, M. Rønning, D. Chen, Y. C. Dai, W. K. Yuan, A. Holmen, Appl. Catal. A, 2007, 323, 135-146.

[69] P. Niebrzydowska, R. Janus, P. Kuśtrowski, S. Jarczewski, A. Wach, A. M. Silvestre-Albero, F. Rodríguez-Reinoso, Carbon, 2013, 64, 252-261.

[70] J. J. Delgado, X.-W. Chen, B. Frank, D. S. Su, R. Schlögl, Catal today, 2012, 186, 93-98.

[71] B. Frank, J. Zhang, R. Blume, R. Schlögl, D. S. Su, Angew. Chem. Int Ed., 2009, 48, 6913-6917.

[72] J. Zhang, D. Su, A. Zhang, D. Wang, R. Schlögl, C. Hébert, Angew. Chem. Int. Ed., 2007, 119, 7319-7323.

[73] W. Qi, W. Liu, B. S. Zhang, X. M. Gu, X. L. Guo, D. S. Su, Angew. Chem. Int. Ed., 2013, 52, 14224-14228.

[74] S. B. Tang, Z. X. Cao, Phys. Chem. Chem. Phys., 2012, 14, 16558-16565.

[75] X. Y. Sun, B. Li, D. S. Su, Chem. Commun., 2014, 50, 11016-11019.

[76] X. Y. Sun, R. Wang, B. S. Zhang, R. Huang, X. Huang, D. S. Su, T. Chen, C. X. Miao, W. M. Yang, ChemCatChem, 2014, 6, 2270-2275.

[77] X. Y. Sun, Y. X. Ding, B. S. Zhang, R. Huang, D. Chen, D. S. Su, ACS Catal., 2015, 5, 2436-2444.

[78] X. Y. Sun, Y. X. Ding, B. S. Zhang, R. Huang, D. S. Su, Chem. Commun., 2015, 51, 9145-9148.
[79] B. Frank, S. Wrabetz, O. V. Khavryuchenko, R. Blume, A. Trunschke, R. Schlögl, ChemPhysChem, 2011, 12, 2709-2713.

[80] A. M. Zheng, Y. Y. Chu, S. H. Li, D. S. Su, F. Deng, Carbon, 2014, 77, 122-129.

[81] L. Liu, Q. F. Deng, B. Agula, X. Zhao, T. Z. Ren, Z. Y. Yuan, Chem. Commun., 2011, 47, 8334-8336.

[82] R. Wang, X. Y. Sun, B. S. Zhang, X. Y. Sun, D. S. Su, Chem. Eur. J., 2014, 20, 6324-6331.

[83] Z. K. Zhao, Y. T. Dai, G. F. Ge, G. R. Wang, Chem. Eur. J, 2015, 21, 8004-8009.

[84] Z. K. Zhao, Y. T. Dai, G. F. Ge, G. R. Wang, AIChE J., 2015, 61, 2543-2561.

[85] Z. Zhao, Y. T. Dai, G. F. Ge, Catal. Sci. Technol., 2015, 5, 1548-1557.

[86] T. T. Thanh, H. Ba, L. Truong-Phuoc, J.-M. Nhut, O. Ersen, D. Begin, I. Janowska, D. L. Nguyen, P. Granger, C. Pham-Huu, J. Mater. Chem. A, 2014, 2, 11349-11357.

[87] Z. K. Zhao, Y. T. Dai, J. Mater. Chem. A, 2014, 2, 13442-13451.

[88] Z. K. Zhao, Y. T. Dai, G. F. Ge, G. R. Wang, ChemCatChem, 2015, 7, 1135-1144.

[89] Z. K. Zhao, Y. T. Dai, J. H. Lin, G. R. Wang, Chem. Mater., 2014, 26, 3151-3161.

[90] L. Liu, Q. F. Deng, B. Agula, T. Z. Ren, Y.-P. Liu, B. Zhaorigetu, Z. Y. Yuan, Catal Today, 2012, 186, 35-41.

[91] L. Liu, Q. F. Deng, Y. P. Liu, T. Z. Ren, Z. Y. Yuan, Catal. Commun., 2011, 16, 81-85.

[92] X. Liu, D. S. Su, R. Schlögl, Carbon, 2008, 46, 547-549.

[93] X. Liu, B. Frank, W. Zhang, T. P. Cotter, R. Schlögl, D. S. Su, Angew. Chem. Int. Ed., 2011, 50, 3318-3322.

[94] D. Y. Jung, H. G. Jang, G. R. Kim, G. J. Kim, Res. Chem. Intermed., 2011, 37, 1145-1156.

[95] N. Keller, N. I. Maksimova, V. V. Roddatis, M. Schur, G. Mestl, Y. V. Butenko, V. L. Kuznetsov, R. Schlögl, Angew. Chem. Int. Ed., 2002, 41, 1885-1888.

[96] D. S. Su, N. Maksimova, J. J. Delgado, N. Keller, G. Mestl, M. J. Ledoux, R. Schlögl, Catal. Today, 2005, 102, 110-114.

[97] D. S. Su, J. J. Delgado, X. Liu, D. Wang, R. Schlögl, L. F. Wang, Z. Zhang, Z. Shan, F. S. Xiao, Chem. Asian J., 2009, 4, 1108-1113.

[98] V. Zarubina, H. Talebi, C. Nederlof, F. Kapteijn, M. Makkee, I. Melián-Cabrera, Carbon, 2014, 77, 329-340.

[99] M. F. R. Pereira, J. L. Figueiredo, J. J. Órfão, P. Serp, P. Kalck, Y. Kihn, Carbon, 2004, 42, 2807-2813.

[100] J. W. Diao, H. W. Liu, J. Wang, Z. B. Feng, T. Chen, C. X. Miao, W. M. Yang, D. S. Su, Chem. Commun., 2015, 51, 3423-3425.

[101] Z. J. Sui, T. J. Zhao, J. H. Zhou, P. Li, Y. C. Dai, Chin. J. Catal., 2005, 26, 521-526.

[102] M. F. R. Pereira, J. J. M. Órfão, J. L. Figueiredo, Carbon, 2002, 40, 2393-2401.

[103] I. Gniot, P. Kirszensztejn, M. Kozłowski, Appl. Catal. A, 2009, 362, 67-74.

[104] M. F. R. Pereira, J. J. M. Órfão, J. L.Figueiredo, Colloids Surf. A, 2004, 241, 165-171.

[105] A. Malaika, P. Rechnia, B. Krzyżyńska, M. Kozłowski, Microporous Mesoporous Mater., 2012, 163, 300-306.

[106] C. D. Liang, H. Xie, V. Schwartz, J. Howe, S. Dai, S. H. Overbury, J. Am. Chem. Soc., 2009, 131, 7735-7741.

[107] L. F. Wang, J. J. Delgado, B. Frank, Z. Zhang, Z. C. Shan, D. S. Su, F. S. Xiao, ChemSusChem, 2012, 5, 687-693.

[108] N. Xiao, Y. Zhou, Z. Ling, Z. B. Zhao, J. S. Qiu, Carbon, 2013, 60, 514-522.

[109] L. F. Wang, J. Zhang, D. S. Su, Y. Y. Ji, X. J. Cao, F. S. Xiao, Chem. Mater., 2007, 19, 2894-2897. 
[110] J. J. Delgado, X. W. Chen, D. S. Su, S. B. A. Hamid, R. Schlögl, J. Nanosci. Nanotechnol., 2007, 7, 3495-3501.

[111] H. Yuan, Z. H. Sun, H. Y. Liu, B. S. Zhang, C. L. Chen, H. H. Wang, Z. M. Yang, J. S. Zhang, F. Wei, D. S. Su, ChemCatChem, 2013, 5, 1713-1717.

[112] J. J. Delgado, D. S. Su, G. Rebmann, N. Keller, A. Gajovic, R. Schlögl, J. Catal., 2006, 244, 126-129.

[113] J. Zhang, R. Wang, E. Z. Liu, X. F. Gao, Z. H. Sun, F. S. Xiao, F. Girgsdies, D. S. Su, Angew. Chem. Int. Ed., 2012, 51, 7581-7585.

[114] P. Li, T. Li, J. H. Zhou, Z. J. Sui, Y. C. Dai, W. K. Yuan, D. Chen, Microporous Mesoporous Mater., 2006, 95, 1-7.

[115] J. Wang, H. Y. Liu, J. Y. Diao, X. M. Gu, H. H. Wang, J. F. Rong, B. N. Zong, D. S. Su, J. Mater. Chem. A, 2015, 3, 2305-2313.

[116] Y. Ito, H. J. Qiu, T. Fujita, Y. Tanabe, K. Tanigaki, M. W. Chen, Adv. Mater., 2014, 26, 4145-4150.

[117] K. P. Gong, F. Du, Z. H. Xia, M. Durstock, L. M. Dai, Science, 2009, 323, 760-764.

[118] X. H. Li, M. Antonietti, Chem. Soc. Rev., 2013, 42, 6593-6604.

[119] H. B. Wang, T. Maiyalagan, X. Wang, ACS Catal., 2012, 2, 781-794.

[120] S. Zhang, P. Kang, S. Ubnoske, M. K. Brennaman, N. Song, R. L. House, J. T. Glass, T. J. Meyer, J. Am. Chem. Soc., 2014, 136, 7845-7848.

[121] M. Park, J. Ryu, Y. Kim, J. Cho, Energy Environ. Sci., 2014, 7, 3727-3735.

[122] L. F. Velasco, J. C. Lima, C. Ania, Angew. Chem. Int. Ed., 2014, 53, 4146-4148.

[123] K. N. Wood, R. O'Hayre, S. Pylypenko, Energy Environ. Sci., 2014, 7, 1212-1249.

[124] W. J. Lee, U. N. Maiti, J. M. Lee, J. Lim, T. H. Han, S. O. Kim, Chem. Commun., 2014, 50, 6818-6830.

[125] Z. H. Sheng, L. Shao, J. J. Chen, W. J. Bao, F. B. Wang, X. H. Xia, ACS Nano, 2011, 5, 4350-4358.

[126] J. T. Jin, X. G. Fu, Q. Liu, Y. R. Liu, Z. Y. Wei, K. X. Niu, J. Y. Zhang, ACS Nano, 2013, 7, 4764-4773.

[127] Z. Y. Lin, G. Waller, Y. Liu, M. L. Liu, C. P. Wong, Adv. Energy Mater., 2012, 2, 884-888.

[128] Z. K. Zhao, Y. T. Dai, G. F. Ge, X. W. Guo, G. R. Wang, Phys. Chem. Chem. Phys., 2015, 17, 18895-18899.

[129] Z. K. Zhao, Y. T. Dai, G. F. Ge, X. W. Guo, G. R. Wang, RSC Adv., 2015, 5, 53095-53099.

[130] Z. K. Zhao, Y. T. Dai, G. F. Ge, X. W. Guo, G. R. Wang, Green Chem.,
2015, 17, 3723-3727.

[131] Z. K. Zhao, Y. T. Dai, G. F. Ge, Q. Mao, Z. M. Rong, G. R. Wang, ChemCatChem, 2015, 7, 1070-1077.

[132] C. Duong-Viet, H. Ba, Y. F. Liu, L. Truong-Phuoc, J. M. Nhut, C. Pham-Huu, Chin. J. Catal., 2014, 35, 906-913.

[133] H. Ba, Y. F. Liu, X. K. Mu, W. H. Doh, J. M. Nhut, P. Granger, C. Pham-Huu, Appl. Catal. A, 2015, 499, 217-226.

[134] H. Y. Liu, J. Y. Diao, Q. Wang, S. Y. Gu, T. Chen, C. X. Miao, W. M. Yang, D. S. Su, Chem. Commun., 2014, 50, 7810-7812.

[135] X. Y. Sun, R. Wang, B. S. Zhang, R. Huang, X. Huang, D. S. Su, T. Chen, C. X. Miao, W. M. Yang, ChemCatChem, 2014, 6, 2270-2275.

[136] J. J. Delgado, X. Chen, J. P. Tessonnier, M. E. Schuster, E. Del Rio, R. Schlögl, D. S. Su, Catal. Today, 2010, 150, 49-54.

[137] R. Huang, C. H. Liang, D. S. Su, B. Zong, J. F. Rong, Catal. Today, 2015, 249, 161-166.

[138] A. Rinaldi, J. Zhang, B. Frank, D. S. Su, S. B. Abd Hamid, R. Schlögl, ChemSusChem, 2010, 3, 254-260.

[139] M. F. R. Pereira, J. J. M. Orfao, J. L. Figueiredo, Appl. Catal. A, 1999, 184, 153-160.

[140] J. d. J. D. Velásquez, L. M. C. Suárez, J. L. Figueiredo, Appl. Catal. A, 2006, 311, 51-57.

[141] N. V. Qui, P. Scholz, T. F. Krech, T. Keller, K. Pollok, B. Ondruschka, Catal. Commun., 2011, 12, 464-469.

[142] D. S. Su, N. I. Maksimova, G. Mestl, V. L. Kuznetsov, V. Keller, R. Schlögl, N. Keller, Carbon, 2007, 45, 2145-2151.

[143] P. Janus, R. Janus, P. Kuśtrowski, S. Jarczewski, A. Wach, A. M. Silvestre-Albero, F. Rodríguez-Reinoso, Catal. Today, 2014, 235, 201-209.

[144] Z. J. Sui, J. H. Zhou, Y. C. Dai, W. K. Yuan, Catal. Today, 2005, 106, 90-94.

[145] Y. Marco, L. Roldán, E. Muñoz, E. García-Bordejé, ChemSusChem, 2014, 7, 2496-2504.

[146] V. Schwartz, H. Xie, H. M. Meyer, S. H. Overbury, C. D. Liang, Carbon, 2011, 49, 659-668.

[147] J. Y. Diao, H. Y. Liu, Z. B. Feng, Y. J.Zhang, T. Chen, C. X. Miao, W. M. Yang, D. S. Su, Catal. Sci. Technol., 2015, 5, 4950-4953.

[148] Z. K. Zhao, W. Z. Li, Y. T. Dai, G. F. Ge, X. W. Guo, G. R. Wang, ACS Sust. Chem. Eng., 2015, 3, 3355-3364.

[149] H. Ba, L. Truong-Phuoc, Y. F. Liu, C. Duong-Viet, J. M. Nhut, L. Nguyen-Dinh, P. Granger, C. Pham-Huu, Carbon, 2016, 96, 1060-1069.

\title{
烷烃脱氢制烯烃用碳催化剂的微结构和表面化学调控研究进展
}

\author{
赵忠奎*，葛桂芳，李伟作，郭新闻，王桂茹 \\ 大连理工大学化工与环境生命学部精细化工国家重点实验室, 辽宁大连116024
}

摘要: 烯烃是重要的大宗有机化工原料, 广泛用于塑料、树脂、橡胶等高分子材料和基础有机化工产品和中间体的生产. 同 时, 烯烃也是重要的精细化工原料和中间体, 广泛用于染料、医药、香料、农用化学品、水性油墨和感光树脂等精细化工 领域. 长链烯烃通常是由小分子烯烃聚合制得, 而小分子烯烃和苯乙烯的合成在学术界和工业界备受关注. 在脱氢、裂解、 脱水等诸多合成方法中, 烷烃脱氢制烯烃是直接而中的路线, 包括直接脱氢和氧化脱氢. 小分子烷烃和乙苯催化脱氢制备 对应的烯烃, 尤其是乙苯制苯乙烯, 目前工业上主要采用铁基催化剂催化直接脱氢工艺. 积炭失活是该工艺面临的严峻挑 战. 工业上采用引入大量过热水蒸气的方法来解决这一难题, 同时, 还可以为脱氢反应提供热量. 但是, 这势必造成巨大的 能耗和反应器容积效率的显著降低. 氧化脱氢工艺是放热反应, 并可有效抑制积炭, 但又存在过氧化所致的低选择性的问 题. 直接脱氢和氧化脱氢各有利弊. 目前, 科学家和工业界都在扬长避短, 开展两种脱氢工艺的新结构高性能催化剂的研 究, 并取得了长足进展.

碳催化是近年来发展起来的一类重要的无机非金属固相催化剂, 在光催化、电催化, 以及热催化领域得到了广泛关注, 
同时也是材料领域研究的前沿和热点. 碳材料, 尤其是纳米碳, 在诸多反应中展示出了比常规金属催化剂更好的催化性能, 且具有可持续的特征. 因此, 碳催化具有广阔的发展空间和巨大的应用前景. 众所周知, 固体催化剂的催化性能重要依赖 于催化剂表面催化活性位的性质及其可及性. 元素组成、化学状态及缺陷边角特征决定着活性位的性质, 而形貌、尺寸、 形状、纹理、表面结构等催化剂的微结构特征决定着固相催化剂活性位的可及性. 因此, 探索有效的方法和策略, 来调节 固相催化剂的微结构和表面化学性质, 已成为催化学术研究的热点领域. 碳材料的表界面和边角的官能团和结构缺陷是 催化反应的活性位. 对于烷烃脱氢反应, 碳材料的表界面羰基和结构缺陷是催化剂的活性位, 而杂原子掺杂可以调控活性 位的电子结构.

本文综述了烷烃脱氢用碳催化剂微结构和表面化学调控方法和效果的最新研究进展, 并讨论了烷烃脱氢碳催化材料 的微结构和表面化学性质调控的重要性和严峻挑战. 通过碳材料合成中前驱体的优选、合成方法和策略的创新, 以及通过 后处理的方法, 均可有效调控碳催化剂的微结构和表面化学性质, 从而调控其烷烃脱氢催化性能. 碳催化用于烷烃脱氢反 应制烯烃, 尤其是直接脱氢, 前景看好. 目前, 研究的碳催化剂多为粉末状, 用于固定床, 存在流体阻力大、压力降高、操作 困难的问题, 并有可能阻塞床层, 造成安全隐患; 用于流化床, 粉末碳易于团聚, 催化剂过滤分离困难, 流失严重. 纳米碳基 整体式催化剂可以是碳催化的未来发展方向. 但是, 目前才刚刚起步. 碳基整体式催化剂活性单元本身可及活性位的性质 及活性单元的分散性、抗脱落性和整体式催化剂的机械强度、导热性等诸多问题需要深入研究和探讨.

总之, 碳催化烷烃脱氢, 尤其是无氧化剂、无水蒸气条件下的直接脱氢, 是经济、节能、清洁、高效的烯烃生产方法, 具 有广阔的发展空间和美好前景. 微结构和化学性质的调变是调控固相催化剂催化活性位性质和可接近性的重要方法, 碳 催化材料及整体式催化剂的碳基活性单元微结构和化学性质的调控是实现其催化性能调控的有效策略.

关键词: 碳催化; 微结构; 表面化学; 调控; 脱氢; 烯烃

收稿日期: 2016-01-13 接受日期: 2016-02-22. 出版日期: 2016-05-05.

*通讯联系人. 电话: (0411)84986354; 传真: (0411)84986354; 电子信箱: zkzhao@dlut.edu.cn

基金来源：国家自然科学基金 (21276041); 教育部新世纪优秀人才支持计划 (NCET-12-0079); 辽宁省自然科学基金 (2015020200); 中央高校基本科研业务费专项资金 (DUT15LK41).

本文的英文电子版由Elsevier出版社在ScienceDirect上出版(http://www.sciencedirect.com/science/journal/18722067). 